\title{
Water balance estimation in high Alpine terrain by combining distributed modeling and a neural network approach (Berchtesgaden Alps, Germany)
}

\author{
G. Kraller ${ }^{1}$, M. Warscher ${ }^{3}$, H. Kunstmann ${ }^{2,3}$, S. Vogl $^{2,3}$, T. Marke ${ }^{1}$, and U. Strasser ${ }^{1}$ \\ ${ }^{1}$ Institute for Geography and Regional Sciences, Karl-Franzens University of Graz, Heinrichstraße 36, 8010 Graz, Austria \\ ${ }^{2}$ Institute for Geography, University of Augsburg, Universitätsstr. 10, 86159 Augsburg, Germany \\ ${ }^{3}$ Institute of Meteorology and Climate Research (IMK-IFU), Karlsruhe Institute of Technology (KIT), Kreuzeckbahnstr. 19, \\ 82467 Garmisch-Partenkirchen, Germany
}

Correspondence to: G. Kraller (gabriele.kraller@uni-graz.at)

Received: 13 December 2011 - Published in Hydrol. Earth Syst. Sci. Discuss.: 5 January 2012

Revised: 26 May 2012 - Accepted: 11 June 2012 - Published: 9 July 2012

\begin{abstract}
The water balance in high Alpine regions is often characterized by significant variation of meteorological variables in space and time, a complex hydrogeological situation and steep gradients. The system is even more complex when the rock composition is dominated by soluble limestone, because unknown underground flow conditions and flow directions lead to unknown storage quantities. Reliable distributed modeling cannot be implemented by traditional approaches due to unknown storage processes at local and catchment scale. We present an artificial neural network extension of a distributed hydrological model (WaSiM-ETH) that allows to account for subsurface water transfer in a karstic environment. The extension was developed for the Alpine catchment of the river "Berchtesgadener Ache" (Berchtesgaden Alps, Germany), which is characterized by extreme topography and calcareous rocks. The model assumes porous conditions and does not account for karstic environments, resulting in systematic mismatch of modeled and measured runoff in discharge curves at the outlet points of neighboring high alpine subbasins. Various precipitation interpolation methods did not allow to explain systematic mismatches, and unknown subsurface hydrological processes were concluded as the underlying reason. We introduce a new method that allows to describe the unknown subsurface boundary fluxes, and account for them in the hydrological model. This is achieved by an artificial neural network approach (ANN), where four input variables are taken to calculate the unknown subsurface storage conditions. This was first developed for
\end{abstract}

the high Alpine subbasin Königsseer Ache to improve the monthly water balance. We explicitly derive the algebraic transfer function of an artificial neural net to calculate the missing boundary fluxes. The result of the ANN is then implemented in the groundwater module of the hydrological model as boundary flux, and considered during the consecutive model process. We tested several ANN setups in different time increments to investigate ANN performance and to examine resulting runoff dynamics of the hydrological model. The ANN with 5-day time increment showed best results in reproducing the observed water storage data $\left(r^{2}=0.6\right)$. The influx of the 20-day ANN showed best results in the hydrological model correction. The boundary influx in the subbasin improved the hydrological model, as performance increased from NSE $=0.48$ to NSE $=0.57$ for subbasin Königsseetal, from NSE $=0.22$ to NSE $=0.49$ for subbasin Berchtesgadener Ache, and from NSE $=0.56$ to NSE $=0.66$ for the whole catchment within the test period. This combined approach allows distributed quantification of water balance components including subsurface water transfer.

\section{Introduction}

Alpine catchments are very important albeit vulnerable landscapes. Most of the major European rivers have their headwaters in Alpine catchments, and their discharge is transported via river systems to lower-lying areas (EEA, 2007). 
The Alps are crucial for water accumulation and water supply (e.g. Viviroli and Weingartner, 2004). For sustainable water management of water resources in alpine areas, it is imperative to understand the hydrological processes, their quantities and dynamics. Distributed hydrological modeling has become an important tool for describing the water balance in catchments (e.g. Goldscheider, 2011). However, these methods face challenges in Alpine areas, on account of high altitudinal gradients, variation of meteorological parameters in time and scale, snow cover dynamics, and unknown subsurface water fluxes and storages. The situation is even more complex when the mountain ranges within a watershed consist of soluble limestone dissected by small fractures and dominant flow paths up to caves and numerous spring locations, as is the case for this study area. The duality of karst, enfolding slow and fast infiltration, slow and fast groundwater flow, and unknown storage leads to heterogeneous water flow in the unsaturated and saturated zone (Attkinson, 1977; Bakalowicz, 2005; Kiraly, 2003; Sauter et al., 2006; White, 2002, 2003). Many approaches at different temporal and spatial scales deal with the modeling of hydrological processes in karst aquifers (e.g. Teutsch and Sauter, 1991). Spring hydrograph, chemograph, and tracer breakthrough curve analysis focus on small-scale effects of karst conduits to define the size and the characteristics of one individual spring aquifer (Birk et al., 2004; Einsiedl, 2005; Geyer et al., 2008; Bonacci, 2004; Hauns et al., 2001; Kovacs et al., 2001; Grasso and Jeannin, 2002; Maloszweski et al., 2005; Weiler et al., 2003). Other approaches concentrate on karst genesis or theoretical conduit flow (Sauter et al., 2006; Romanov et al., 2004; Ford, 2003). Distributive methods, such as "Single Continuum Porous Equivalent", "Double Continuum Porous Equivalent", "Discrete Single Fracture Sets" or "Discrete Multiple Fracture Set", "Hybrid Models" (Sauter et al., 2006) attempt to take into account the heterogeneity of karst aquifers within single conduits or parameter fields in a spatial continuum, however mainly concentrate on modeling water fluxes within the saturated zone. The duality of karst makes it tremendously difficult to find an adequate parameterization to successfully model groundwater flow in present distributed models, which principally assume porous conditions (Kiraly, 2003). In the past, many studies have applied distributed groundwater models in karst environments (Scanlon et al., 2003; Caroll et al., 2008; Martinez Santos and Andreu, 2010; Worthington, 2003), or other conceptual approaches such as in Rimmer and Salingar (2006). These approaches do not deal with the effects of a massif Alpine karst aquifer itself on the hydrology of a catchment or subcatchment. Barthel (2011) recommends groundwater studies that focus on the catchment scale. Kunstmann et al. (2006b) and Kunstmann and Stadler (2005) applied the distributed hydrological model WaSiM-ETH in Alpine catchments. To the author's knowledge, so far, no attempt has been made to examine the complete water balance of an Alpine karstified watershed and its sub-catchments by applying a distributed hydrological model to determine possible subsurface boundary fluxes. White and White (2003) describe groundwater basins as total recharge areas including all surface stream catchments that drain into the conduit system of a spring. Overall, karst ground water basins from springs do not correlate with the boundaries of overlying surface water basins; they may also be linked by piracy or spillover routes. Conduits develop across surface water divides thereby transmitting water to or from other nearby surface water basins. Furthermore, groundwater basins have one set of flow paths active during base flow conditions and quite a different set of flow paths during flood flow conditions (White and White, 2003). Our study area is characterized by hundreds of springs connected to fracture, conduit or cave systems with an unknown set of active or inactive flow paths. We assume, however, that water fluxes in an high Alpine $1000 \mathrm{~m}$ banked limestone aquifer with an inclined stratification can lead to groundwater inflow, outflow or redistribution on an even larger scale than spring basins - at catchment scale, where subbasins cover valleys in mountainous regions, and that this affects river runoff within those subbasins and consecutive streams.

\section{Summary of the new approach}

Within the study area, each of the three high Alpine head subbasins is unique in subsurface hydrological systems (Kraller et al., 2011), and measured runoff differs significantly between the valleys within the same time period. By applying the hydrological model, we are able to show that high Alpine aquifers do have a tremendous effect on the hydrology of subbasins and that common approaches for distributed modeling (Richards equation, 2-D-groundwater model, Darcy equation and continuity equation) of the water balance perform insufficiently. By analyzing measured runoff and modeling results for precipitation, evapotranspiration and runoff we found systematic data patterns in model mismatch, and, consequently mismatch in modeled and observed water storage in three neighboring subbasins "Klausbachtal", "Wimbachtal" and "Königsseetal" (Fig. 1). This under- and overestimation affects model results in consecutive subbasins (river gauge Berchtesgadener Ache) within the model area and the model area outflow (river gauge St. Leonhard). Different precipitation interpolation approaches did not allow to correct for this mismatch. Thus, we conclude that different storage conditions lead to under- and overestimation of runoff and we developed a method to calculate missing water fluxes with flexible inflow and outflow at subbasin scale. We derive the analytical solution of the artificial neural net to calculate observed water storage that can be implemented in the hydrological model as inflow or outflow in the saturated zone as continuous boundary flux (Fig. 2). The implemented flux is considered in the model run and affects modeled stream discharge of consecutive subbasins. The aim of this study is to improve the monthly water balance in the 


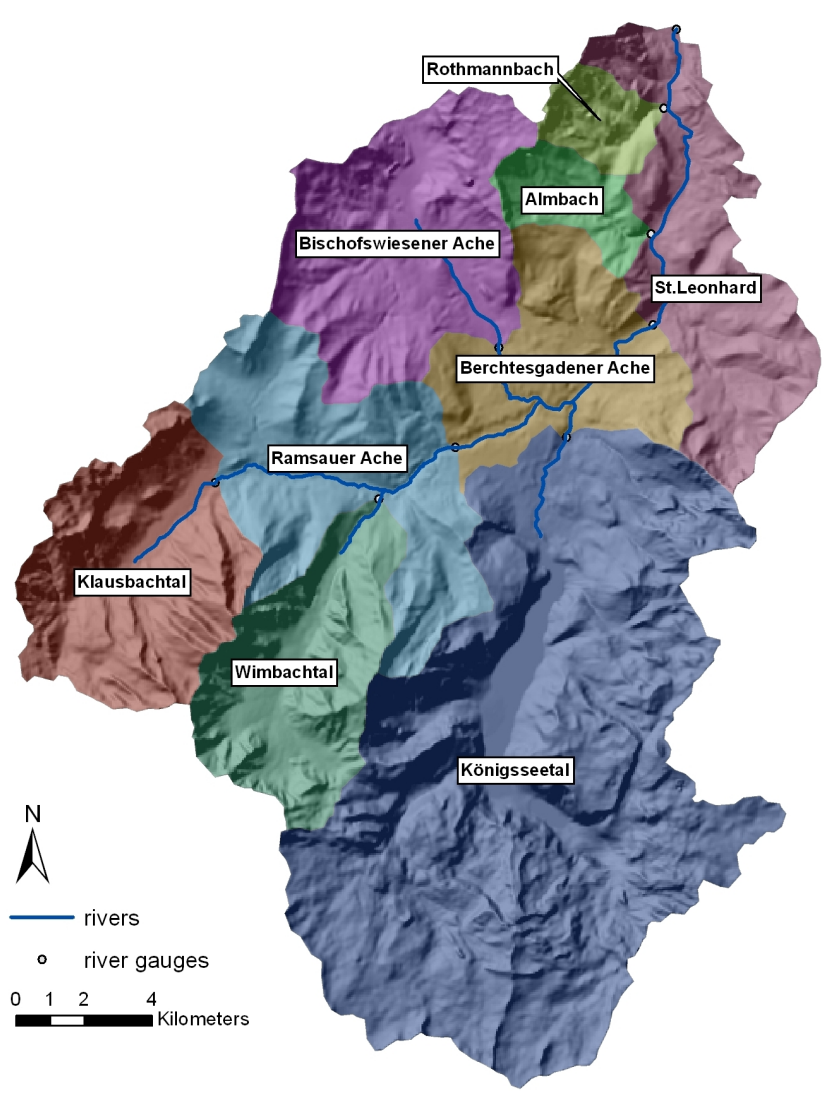

Fig. 1. Study area: river gauges and subbasins.

subbasin Königsseetal and investigate effects on downstream subbasins. Not only does this method permit description of water storage dynamics and resulting groundwater inflow and outflow in karstic terrains, but it also allows to adapt distributed hydrological models to karst dominated watersheds.

\section{Study area and former karst research results}

The study site encompasses the watershed of the river Berchtesgadener Ache and is situated in the Berchtesgaden Alps in the southeast of Germany in the Federal State of Bavaria. The area covers $432 \mathrm{~km}^{2}$ and is mostly German territory. Ten per cent, however, is Austrian national territory. Most of the area can be assigned to the Man and Biosphere Reserve Berchtesgaden, of which the core zone is Berchtesgaden National Park (IUCN Category II) with an area of $210 \mathrm{~km}^{2}$ (Fig. 1). The climate in the area is cooltemperate and humid. Mean temperature is $4.5^{\circ} \mathrm{C}$ in the high Alpine regions and $7.5^{\circ} \mathrm{C}$ for the whole watershed. Precipitation has an altitude-dependent gradient of $47 \mathrm{~mm} / 100 \mathrm{~m}$. Annual precipitation ranges from $1500 \mathrm{~mm}$ in the valleys to up to $2600 \mathrm{~mm}$ in higher elevated regions. Maximum precipitation is $250-350 \mathrm{~mm}$ in July in the high Alpine regions of the test site, albeit high uncertainties exist as only few

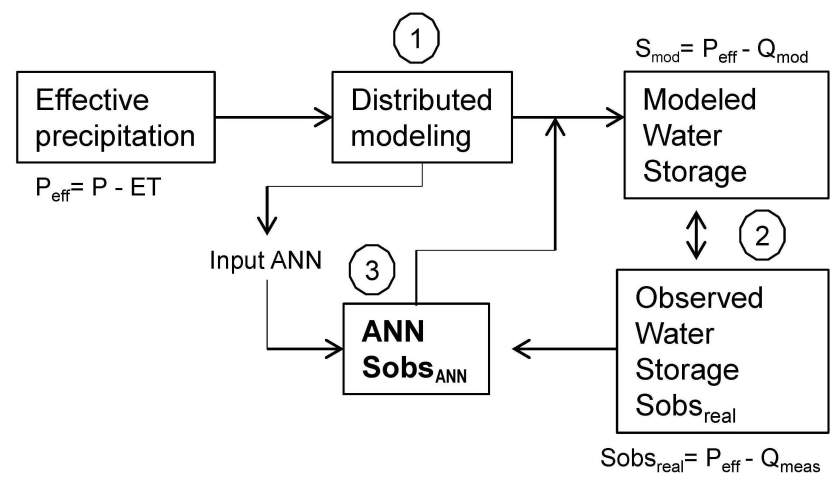

Fig. 2. Overview of the presented method. Effective precipitation results in modeled runoff. Consistent model mismatch was detected due to water storage deviations. Modeled water storage (derived from hydrological model runoff) systematically over/underestimates observed water storage (derived from measured runoff). The observed water storage is then calculated by the ANN and implemented in the groundwater module to account for the observed storage processes. The ANN is applied to the subcatchment Königsseetal.

stations are established in higher regions. The number of days with snow cover is more than 300 per year in peak regions. Dominant biotopes are forest, limestone grasslands, rock and scree, mountain pines and lakes. The Berchtesgaden Alps are situated in the northern limestone Alps and can be seen as a geomorphological unit. The nine associated mountain ranges to the watershed "Berchtesgadener Ache" are shaped in close proximity as plateaus and ridges. Three valleys stretching from south to north, separating four mountain massifs from each other are representative for the area. Dominant rock formations are Triassic Dachstein limestone and Ramsau Dolomite, but Jurassic and Cretaceous rock series are also present (Fig. 3). The banked limestone with a layer thickness of up to $1000 \mathrm{~m}$ covering 500-700 m of Dolomite extends along an altitudinal gradient up to $2100 \mathrm{~m}$. The three main tectonic units in the area are arranged on top of one another: The base Tirolikum is covered by the Tiefjuvavikum which itself lies beneath the Hochjuvavikum. Alpine fold leads to a typical slope and inclined stratigraphy of the existing rock formations. The mountain massifs Hochkalter and Watzmann slightly slope in a northern direction (Fischer, 2005; Langenscheidt, 1994). The soluble limestone has been exposed to karstification processes since the Alpine lift, which took place in different phases. Typical karst phenomena in the region are the presence of dolines, basins, dry stream beds, caves and karrens. The massif karst aquifer in the area is characterized by matrix, fractures and conduits. The epikarst and vadose zones are more dominant than the phreatic zone. Most of the spring discharge is a reaction to precipitation events. A spring horizon at the south shore of a lake shows phreatic behaviour but reacts also to precipitation events. There are no permanent sinking streams within 

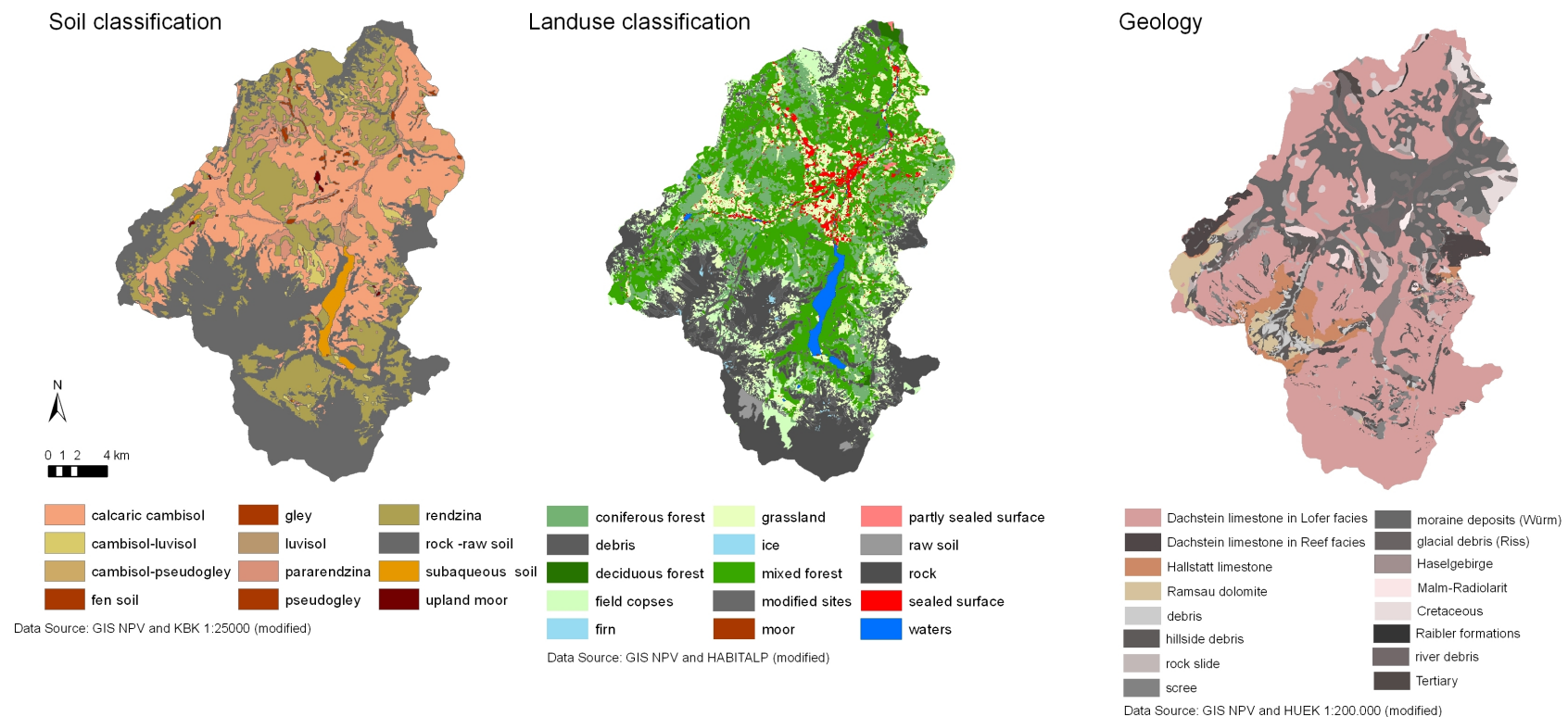

Fig. 3. Soil classification, land use classification and main geological units within the study area.

the study area, but snowmelt and rain immediately infiltrate through swallow holes, especially on karst plateaus. Based on spring locations, the boundary between unsaturated and saturated zone is estimated at an altitude of $601 \mathrm{~m}$ a.s.l. and $1500 \mathrm{~m}$ a.s.l. maximum, but mainly at $700-1000 \mathrm{~m}$ a.s.l. Consequently, the unsaturated zone can be up to $1000 \mathrm{~m}$ in thickness. The eight rivers within the watershed drain the area in a northerly direction. Based on nine river gauges available for the basin, it can be divided into nine subbasins (Fig. 1). Several tracer experiments, a spring database and geological conditions indicate a main groundwater flow direction from the south. Furthermore, groundwater redistribution between subcatchments is also indicated between three neighboring Alpine head subbasins stretch from north to south (Kraller et al., 2011). These subbasins are located in a highly karstified area with a steep terrain. Subbasin Klausbachtal $\left(42.79 \mathrm{~km}^{2}\right)$ is characterized by forests at lower altitudes and high Alpine plateau and ridge karst at higher altitudes. It is bounded by the plateau mountain Reiteralm and mount Hochkalter. Subbasin Wimbachtal $\left(35.69 \mathrm{~km}^{2}\right)$ is filled with Dolomite gravel deposits, forming a porous aquifer with a depth of $300 \mathrm{~m}$. It is surrounded by mounts Hochkalter and Watzmann, which are characterized by a huge carbonate stratum. In the southern part, it is surrounded by dolomite mountains. Subbasin Königsseetal $\left(163.54 \mathrm{~km}^{2}\right)$ is characterized by Lake Königssee $\left(511\right.$ mio $\left.^{3}\right)$ and very steep gradients. It is bounded by mount Watzmann and the Hagengebirge plateau, while to the south it is surrounded by a huge Alpine karst plateau, called "Steinernes Meer". Geologically and hydrologically, these neighboring subbasins show unique geological and hydrological features (Fig. 3).

\section{Distributed modeling in high Alpine terrain}

\subsection{Model setup}

We applied the distributed hydrological model WaSiM-ETH (Schulla, 2012) (Version 8.8.0) in a horizontal resolution of $50 \mathrm{~m}$ and a temporal resolution of $1 \mathrm{~h}$. The basin and borders of the subbasins were derived by the digital elevation model and the location of river gauges. Eight gauges are located in Germany and one in Austria. The model uses physically-based algorithms within its modular system. Precipitation interpolation was done using inverse distance weighting and linear regression linearly combined (IDW weighted with 0.25 ). Interpolation of other meteorological input data was done by elevation dependent regression or IDW. Infiltration is calculated after Peschke (1977), evapotranspiration after Penman-Monteith (Penman, 1948; Monteith, 1975; Brutsaert, 1982), snow cover dynamics are calculated following Strasser (2008). Direct flow (surface runoff) is the sum of infiltration excess, saturation excess and a defined fraction of the snow melt. Vertical soil water fluxes within a defined number of soil layers and depth in the unsaturated zone are described by solving the Richards equation (Richards, 1931). Soil parameterization is done according to Van Genuchten (1976). Interflow is calculated depending on suction, drainable water content and saturated hydraulic conductivity. The lakes are modeled using the fully integrated lake model with connection to the unsaturated and saturated zone. The hydrological model was applied with a 2D groundwater model coupled to the unsaturated zone with a vertical boundary flux. The lower boundary of the unsaturated zone is the depth of the groundwater layer. Horizontal groundwater flow is calculated by the flow equation derived from Darcy's 
law and the continuity equation. The saturated zone is located within the defined soil layers and depth, groundwater level is calculated corresponding to soil water content and previous storage conditions. The aquifer is assumed to be unconfined. Storage conditions within the unsaturated zone are initialized for each discretization layer with a water content corresponding to an hydraulic equilibrium with the groundwater (fluxes are zero) and the groundwater table is assumed to be at a depth of $20 \%$ of the soil column.

In principle, the model environment is not able to account for karstic underground. A porous aquifer is assumed. It represents a substitutional porous media model whose parameters must be interpreted as effective parameters approximating the karstic environment on subcatchment scale (Kunstmann et al., 2006a). Next to numerous free model parameters, sensitive calibration parameters are the recession constant $k_{\text {rec }}$ for the saturated hydraulic conductivity and the interflow drainage density $d_{\mathrm{r}}$ (Schulla, 2012). Discharge routing is done with a kinematic wave approach, including a flow time table, retardation and translation. Due to fast infiltration and high evapotranspiration in bare karst area, we adapted parameters for evapotranspiration over rock surfaces leading to increased evapotranspiration for these areas. Furthermore, we also allowed for macropore-infiltration as it is implemented in the hydrological model after Jansson and Karlberg (2001). Data for soil classification were derived from the existing soil database of the National Park authority and the concept soil map provided by the Bavarian Environment Agency. Land use classification was derived from Lotz (2006) and Corine Land Cover data. Main soil types are cambisol, pararendzina, podsol, ranker and bare rock. We classified 15 land use types and 20 soil types within the model area. Soil stratification was defined for 40 layers with a depth of $0.2 \mathrm{~m}$ to $4.0 \mathrm{~m}$ according the distributed porous approach. Soil depth ranges from 15 to $56 \mathrm{~m}$. Information on the hydraulic saturated conductivity was derived from BGRSGD (2007). Best parameterization for aquifer thickness and the specific storage coefficient were iteratively estimated. Aquifer thickness was assumed to be $15 \mathrm{~m}$. The authors assumed several soil depths and aquifer thicknesses, and got best performance results for the mentioned setup. River courses were derived from the digital elevation model during preprocessing. The discharge data was provided by the Traunstein water management office and the Salzburg hydrographical service. Meteorological input data were provided by 33 weather stations whereby 20 are automatic and 13 are mechanical stations (Table 1 ). The stations are equally distributed in altitude (430-2445 $\mathrm{m}$ a.s.l.) and space throughout the model area (Fig. 4). Several model runs showed that the model is in steady state after several months, so the initialization period was one hydrological year 2001/2002. After model calibration and model validation, the results were used as fitted storage parameters to be read in for the following model runs.

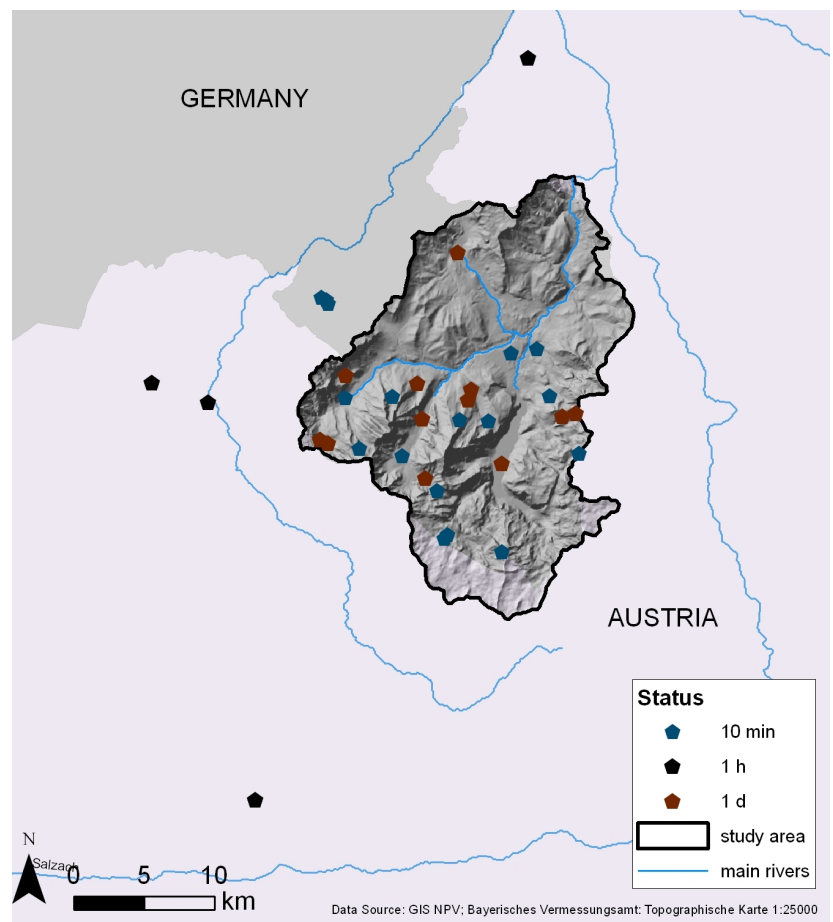

Fig. 4. Locations of weather stations within and outside the study area.

\subsection{Analysis of precipitation interpolation methods}

We found there to be a mass problem in the hydrological model because it is unable to reproduce measured runoff in the Alpine head catchments. Modeling with precipitation correction (factor 0.20 for solid precipitation) resulted in decreasing model performance. Figure 6 shows annual sums of measured runoff and modeled runoff with and without precipitation correction in subbasins Königsseetal, Wimbachtal and Klausbachtal. Without precipitation correction, runoff performance is satisfactory in subbasin Klausbachtal, but measured runoff is underestimated in subbasin Wimbachtal and Königsseetal. Although modeled runoff performance increases slightly in subbasin Wimbachtal when using precipitation correction, it is often overestimated in subbasin Königsseetal and highly overestimated in subbasin Klausbachtal. Table 3 shows the Nash Sutcliffe efficiency of modeled runoff for the validation period with and without precipitation correction. It decreases for all subbasins except subbasin Wimbachtal. When considering all the subbasins, runoff performance is better without precipitation correction. Application of precipitation correction with different factors in each of the subbasins would improve model results. In our opinion, however, there is no meteorological justification to do so. Based on the results of this investigation we decided to model without precipitation correction. Additionally, various interpolation methods to analyze whether precipitation input data were the cause for the deviation or 
Table 1. Location, altitute and parameters and temporal resolution of the meteorological stations used for our investigation.

\begin{tabular}{|c|c|c|c|c|}
\hline Station & $\begin{array}{l}\text { Altitude } \\
\text { [m a.s.l.] }\end{array}$ & Parameters & $\begin{array}{l}\text { Temporal } \\
\text { resolution }\end{array}$ & Operator \\
\hline Reiteralm1 & 1755 & $T, \mathrm{RH}, \mathrm{WS}, \mathrm{WD}$ & $10 \mathrm{~min}$ & LWZ \\
\hline Reiteralm2 & 1670 & $T, \mathrm{RH}, \mathrm{TS}, \mathrm{SD}$ & $10 \mathrm{~min}$ & LWZ \\
\hline Reiteralm3 & 1615 & $T, \mathrm{RH}, P, \mathrm{GR}, \mathrm{RR}, \mathrm{SD}$ & $10 \mathrm{~min}$ & LWZ \\
\hline Hinterseeau & 839 & $T, \mathrm{RH}, \mathrm{WS}, \mathrm{WD}, \mathrm{GR}, \mathrm{RR}, \mathrm{SD}$ & $10 \mathrm{~min}$ & NPV \\
\hline Hinterberghorn & 2270 & $T, \mathrm{RH}, \mathrm{WS}, \mathrm{WD}, \mathrm{GR}, \mathrm{RR}$ & $10 \mathrm{~min}$ & NPV \\
\hline Blaueis & 1651 & $T, \mathrm{RH}, \mathrm{WS}, \mathrm{WD}, \mathrm{GR}, \mathrm{RR}$ & $10 \mathrm{~min}$ & NPV \\
\hline Brunftbergtiefe & 1238 & $T, \mathrm{RH}, P, \mathrm{WS}, \mathrm{WD}, \mathrm{GR}, \mathrm{RR}$ & $10 \mathrm{~min}$ & NPV \\
\hline Trischübl & 1764 & $T, \mathrm{RH}, P, \mathrm{WS}, \mathrm{WD}, \mathrm{GR}, \mathrm{RR}$ & $10 \mathrm{~min}$ & NPV \\
\hline Steinernes Meer & 1900 & $T, \mathrm{RH}, P, \mathrm{WS}, \mathrm{WD}, \mathrm{GR}, \mathrm{RR}$ & $10 \mathrm{~min}$ & NPV \\
\hline Watzmannhaus & 1919 & $T, \mathrm{RH}, \mathrm{WS}, \mathrm{WD}, \mathrm{GR}, \mathrm{RR}$ & $10 \mathrm{~min}$ & LWZ \\
\hline Schönau & 617 & $T, \mathrm{RH}, P, \mathrm{GR}, \mathrm{DR}, \mathrm{SS}, \mathrm{WS}, \mathrm{WD}, \mathrm{AP}$ & $10 \mathrm{~min}$ & Schönau/NPV/DWD \\
\hline Jenner & 1219 & $T, \mathrm{RH}, P, \mathrm{WS}, \mathrm{TS}, \mathrm{SD}$ & $10 \min$ & LWZ \\
\hline Schlunghorn & 2155 & $T, \mathrm{RH}, \mathrm{WS}, \mathrm{WD}, \mathrm{GR}, \mathrm{RR}$ & $10 \min$ & NPV \\
\hline Höllgraben & 653 & $T, \mathrm{RH}, P$ & $10 \mathrm{~min}$ & LWZ \\
\hline Kühroint & 1407 & $T, \mathrm{RH}, P, \mathrm{WS}, \mathrm{WD}, \mathrm{GR}, \mathrm{RR}, \mathrm{TS}, \mathrm{SD}, \mathrm{SWE}$ & $10 \mathrm{~min}$ & LWZ \\
\hline Funtenseetauern & 2445 & $T, \mathrm{RH}, \mathrm{WS}, \mathrm{WD}$ & $10 \mathrm{~min}$ & LWZ \\
\hline Lofer & 625 & $T, P, \mathrm{RH}, \mathrm{WS}, \mathrm{WD}, \mathrm{GR}, \mathrm{SS}, \mathrm{AP}$ & $1 \mathrm{~h}$ & ZAMG \\
\hline LofererAlm & 1623 & $T, P, \mathrm{RH}, \mathrm{WS}, \mathrm{WD}, \mathrm{GR}, \mathrm{SS}, \mathrm{AP}$ & $1 \mathrm{~h}$ & ZAMG \\
\hline SBG Flughafen & 430 & $T, P, \mathrm{RH}, \mathrm{WS}, \mathrm{WD}, \mathrm{GR}, \mathrm{SS}, \mathrm{AP}$ & $1 \mathrm{~h}$ & ZAMG \\
\hline Schmittenhöhe & 1973 & $T, P, \mathrm{RH}, \mathrm{WS}, \mathrm{WD}, \mathrm{GR}, \mathrm{SS}, \mathrm{AP}$ & $1 \mathrm{~h}$ & ZAMG \\
\hline Königsberg Pegel & 699 & $P$ & $1 \mathrm{~d}$ & NPV \\
\hline Schapbach & 953 & $P$ & $1 \mathrm{~d}$ & NPV \\
\hline Kühroint (mech.) & 1418 & $P$ & $1 \mathrm{~d}$ & NPV \\
\hline Lahneralm & 1240 & $P$ & $1 \mathrm{~d}$ & NPV \\
\hline St. Bartholomä & 604 & $P$ & $1 \mathrm{~d}$ & NPV \\
\hline Wimbachschloss & 926 & $P$ & $1 \mathrm{~d}$ & NPV \\
\hline Brunftbergtiefe (mech.) & 1238 & $P$ & $1 \mathrm{~d}$ & NPV \\
\hline Auf dem Gries & 1435 & $P$ & $1 \mathrm{~d}$ & NPV \\
\hline Bindalm & 1119 & $P$ & $1 \mathrm{~d}$ & NPV \\
\hline Eckau & 1015 & $P$ & $1 \mathrm{~d}$ & NPV \\
\hline Lahnwaldfütterung & 840 & $P$ & $1 \mathrm{~d}$ & NPV \\
\hline Mittereis & 1325 & $P$ & $1 \mathrm{~d}$ & NPV \\
\hline Halsalm & 1088 & $P$ & $1 \mathrm{~d}$ & NPV \\
\hline
\end{tabular}

$T=$ air temperature, $\mathrm{RH}=$ relative humidity, $\mathrm{WS}=$ wind speed, $\mathrm{SD}=$ snow depth, $\mathrm{SWE}=$ snow water equivalent, $\mathrm{SS}=$ sunshine duration, $\mathrm{GR}=$ global radiation, $\mathrm{DR}=$ direct radiation, $\mathrm{RR}=$ reflected radiation, $P=$ precipitation, $\mathrm{AP}=$ atmospheric pressure at sea level, $\mathrm{TS}=$ surface temperature, $\mathrm{LWZ}=\mathrm{Bavarian}$ avalanche warning service, NPV = Administration Berchtesgaden National Park, ZAMG = Central Institute for Meteorology and Geodynamics Austria

Table 2. Pecipitation interpolation analysis.

\begin{tabular}{llcccc}
\hline Scale & Time period & $\begin{array}{c}\text { IDW } \\
{[\mathrm{mm}]}\end{array}$ & $\begin{array}{c}\text { REG } \\
{[\mathrm{mm}]}\end{array}$ & $\begin{array}{c}\text { REG + IDW } \\
{[\mathrm{mm}]}\end{array}$ & $\begin{array}{c}\text { Station data (Kühroint) } \\
{[\mathrm{mm}]}\end{array}$ \\
\hline $\begin{array}{l}\text { Subbasin } \\
\text { Station }\end{array}$ & Sum 2006/2007 & 1559 & 1704 & 1643 & - \\
\hline
\end{tabular}

not were investigated. The precipitation interpolation methods inverse distance weighting (IDW), elevation dependent regression(REG) and a linear combination of IDW and elevation dependent regression (weighting factor IDW: 0.25 ) were tested for the annual sum of precipitation in subbasin
Königsseetal. Annual sums of interpolated precipitation were $1559 \mathrm{~mm}$ for IDW, $1704 \mathrm{~mm}$ for regression and $1643 \mathrm{~mm}$ for the linear combination of both methods (Table 2). IDW shows the lowest value because the elevation dependency of the precipitation was not considered $(1559 \mathrm{~mm})$. However, 
Table 3. Nash Sutcliffe efficiency (NSE) in the calibration period, validation period and validation period with precipitation correction for several subbasins.

\begin{tabular}{|c|c|c|c|c|}
\hline No. & Subbasin & $\begin{array}{r}\text { Cal. period } \\
\text { linNSE/logNSE }\end{array}$ & $\begin{array}{r}\text { Val. period } \\
\text { linNSE/logNSE }\end{array}$ & $\begin{array}{r}\text { Val. period with } \\
\text { precipitation } \\
\text { orrection } \\
\text { clinNSE/logNSE }\end{array}$ \\
\hline 1 & Klausbachtal & $0.58 / 0.78$ & $0.63 / 0.81$ & $-3.68 / 0.50$ \\
\hline 2 & Wimbachtal & $-0.98 /-0.98$ & $-0.0008 / 0.16$ & $-0.008 / 0.39$ \\
\hline 3 & Ramsauer Ache & $0.36 / 0.36$ & $0.18 / 0.65$ & $-6.82 / 0.65$ \\
\hline 4 & Königsseetal & $0.66 / 0.51$ & $0.56 / 0.64$ & $-0.53 / 0.45$ \\
\hline 6 & Berchtesgadener Ache & $0.55 / 0.22$ & $0.32 /-0.04$ & $-0.61 / 0.63$ \\
\hline 9 & St. Leonhard & $0.54 / 0.51$ & $0.59 / 0.52$ & $-1.15 / 0.27$ \\
\hline
\end{tabular}

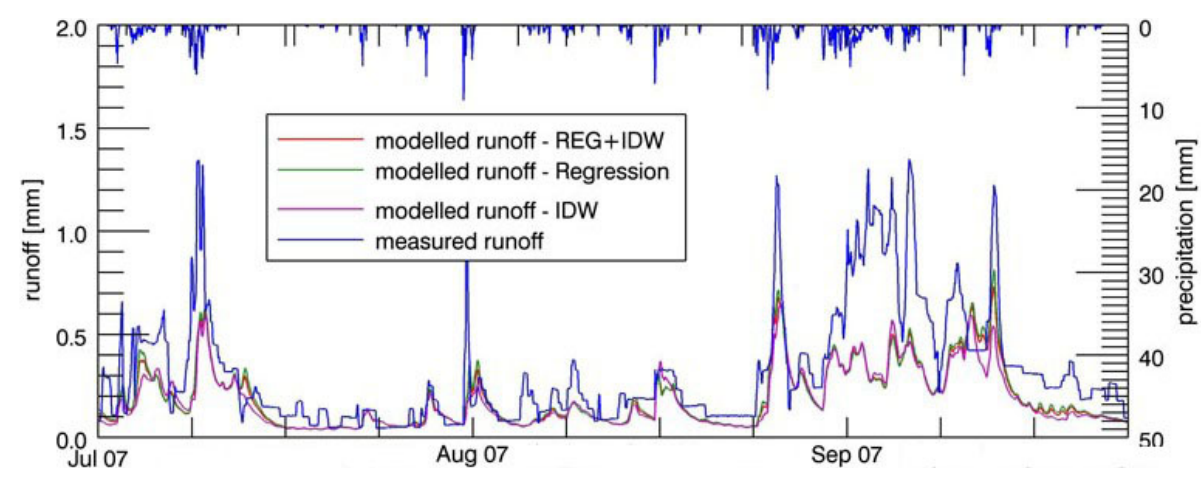

Fig. 5. Comparison of different interpolation methods in subbasin Königsseetal. Inverse distance weighting (IDW), elevation dependent regression (REG) and both methods linearly combined (IDW + REG).

analyses of station data within the area proved gradient dependency of precipitation amount. In high Alpine terrain, IDW was not considered appropriate for the application. Regression showed the highest value, because it did not reproduce station data $(1704 \mathrm{~mm})$. The combined method gives a value between the two other methods, because it takes into account elevation dependency and station data $(1643 \mathrm{~mm})$. We analyzed both methods for one station by comparing the overall mean from 2001-2010. The analysis revealed that REG + IDW could best reproduce the station data. Figure 5 shows modeled runoff resulting from the different interpolation methods. Runoff dynamics differ slightly, and none of the methods resulted in improved model results. In this terrain, model mismatch cannot be put down to a single cause. We are aware that there are highly dynamic meteorological processes in high Alpine terrain and cannot exclude that these effects may partly be responsible for the model mismatch. However, as the study area is located in profoundly karstic terrain, we also concluded unknown storage processes to be the the main cause for the model mismatch.

\subsection{Outcomes distributed modeling - identification and quantification of boundary fluxes}

In a first step, we analyzed annual sums and overall means of measured runoff and modeled precipitation, evapotranspiration and runoff at the river gauges of the three high Alpine neighboring head subbasins Klausbachtal, Wimbachtal and Königsseetal (Table 4). Annual sums of measured runoff ranged from $996 \mathrm{~mm}$ to $1375 \mathrm{~mm}$ in subbasin Klausbachtal (mean 1086), from 1045 to $2808 \mathrm{~mm}$ in subbasin Wimbachtal (mean 1882) and from 1197 to $1831 \mathrm{~mm}$ (mean 1443) in subbasin Königsseetal. Annual sums of measured runoff differed significantly in these subcatchments. Precipitation ranged from 1575 to $2154 \mathrm{~mm}$ in subbasin Klausbachtal, from 1565 to $1983 \mathrm{~mm}$ in subbasin Wimbachtal and from 1532 to $1923 \mathrm{~mm}$ in subbasin Königsseetal, resulting in an overall mean of $1605 \mathrm{~mm}$ (Klausbachtal), $1560 \mathrm{~mm}$ (Wimbachtal) and $1551 \mathrm{~mm}$ (Königsseetal), respectively. Mean annual evapotranspiration was $306 \mathrm{~mm}$ for subbasin Klausbachtal, $306 \mathrm{~mm}$ for subbasin Wimbachtal and $349 \mathrm{~mm}$ for subbasin Königsseetal. The measured runoff indicates a unique hydrology in each valley. After hydrological model calibration, model runs result in equally calculated annual sums of modeled runoff, dependent on precipiation input. Mean annual modeled discharge was $1254 \mathrm{~mm}$ in subbasin Klausbachtal, 


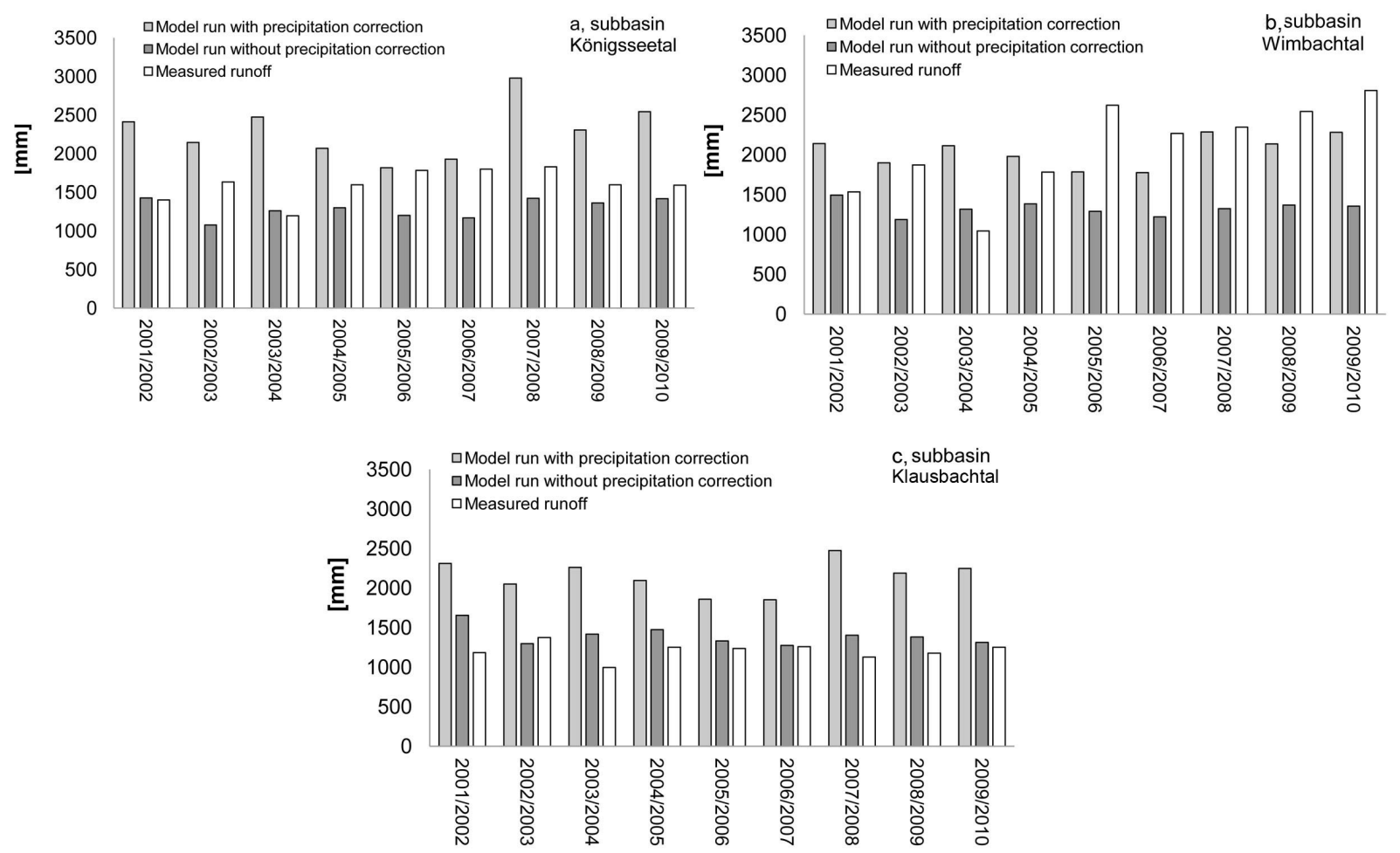

Fig. 6. Annual sums of measured runoff, modeled runoff and modeled runoff with precipitation correction for subbasins Klausbachtal, Wimbachtal and Königsseetal.

$1194 \mathrm{~mm}$ in subbasin Wimbachtal and $1164 \mathrm{~mm}$ in subbasin Königsseetal. Consequently, a systematic over- and underestimation of discharge was found in these subbasins when comparing modeled to measured runoff (Fig. 7). Based on analyses of several precipitation interpolation approaches, we assume the different annual sums of measured runoff in subbasin Klausbachtal, Wimbachtal and Königsseetal to be the result of subsurface boundary fluxes that were not taken into account by the hydrological model, leading to under and overestimation of measured runoff during model runs. Since it is the characteristic subsurface conditions and resulting water fluxes that influence the water balance in karst aquifers, the monthly sums of water storage for subbasins Klausbachtal, Wimbachtal and Königsseetal were analyzed in model runs and reality to gain more information about the annual dynamics of the water storage. By subtracting the runoff $(Q)$ from the incoming effective precipitation (Eq. 1) storage reduction or buildup is expressed and is assumed to be positive in winter and summer (snow storage and soil storage) and negative in spring and autumn (snow melt and soil storage decrease), leading to a systematic pattern throughout one year. Deviations from the assumed pattern for the observed water storage may give insights into groundwater inflow, outflow or redistribution at subbasin scale due to subsurface water fluxes. Monthly sums of observed and modeled water storage were analyzed (Eqs. 2 and 3).
$P_{\mathrm{eff}}(t)=P(t)-\mathrm{ET}(t)$

$S_{\text {mod }}(t)=P_{\text {eff }}(t)-Q_{\text {mod }}(t)$

$S_{\mathrm{obs}_{\text {real }}}(t)=P_{\text {eff }}(t)-Q_{\text {meas }}(t)$

Figure $8 \mathrm{a}$ shows the water storage modeled for the subcatchments Klausbachtal, Wimbachtal and Königsseetal in monthly sums for the summer period in years 2002 to 2011. Storage is mostly positive as there is less runoff than precipitation income (soil storage buildup) in the hydrological model. The monthly sums of modeled runoff show positive values. Figure $8 \mathrm{~b}$ shows the water storage derived from the measured runoff. It shows negative peaks during summer for subbasins Wimbachtal and Königsseetal. There is more runoff than precipitation coming in, indicating groundwater inflow and explaining the amount of measured annual runoff. In subbasin Klausbachtal, there is less soil storage and snow melt, indicating groundwater outflow and explaining the annual lack of water. Table 5 shows the maximum, minimum and mean of monthly modeled and measured water storage. In subbasin Klausbachtal, mean of observed water storage is positive $(21 \mathrm{~mm})$, indicating water outflow from the subbasin. It is underestimated by the hydrological model $(4 \mathrm{~mm})$, because water outflow is not calculated and all incoming precipitation is routed to the stream. In subbasins Wimbachtal and Königsseetal, mean water storage is negative $(-53 \mathrm{~mm}$; 


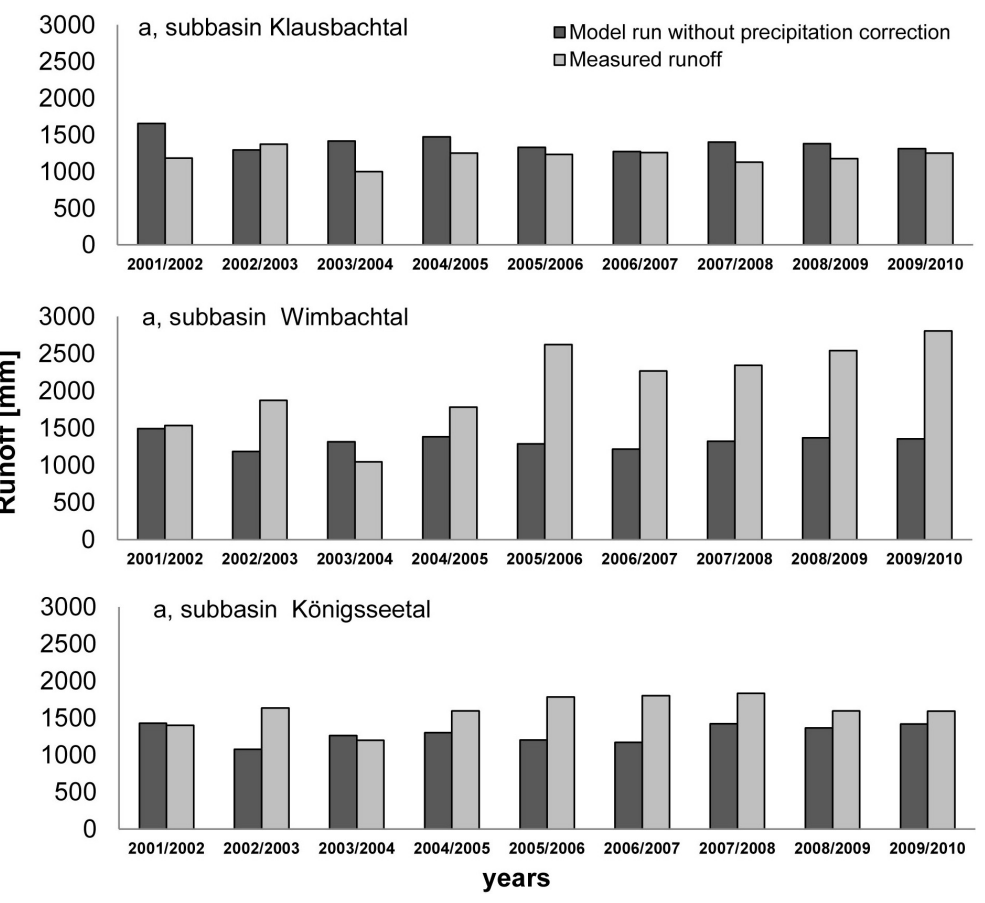

Fig. 7. Annual sums of modeled and measured discharge subbasins Klausbachtal, Wimbachtal and Königsseetal before ANN correction.
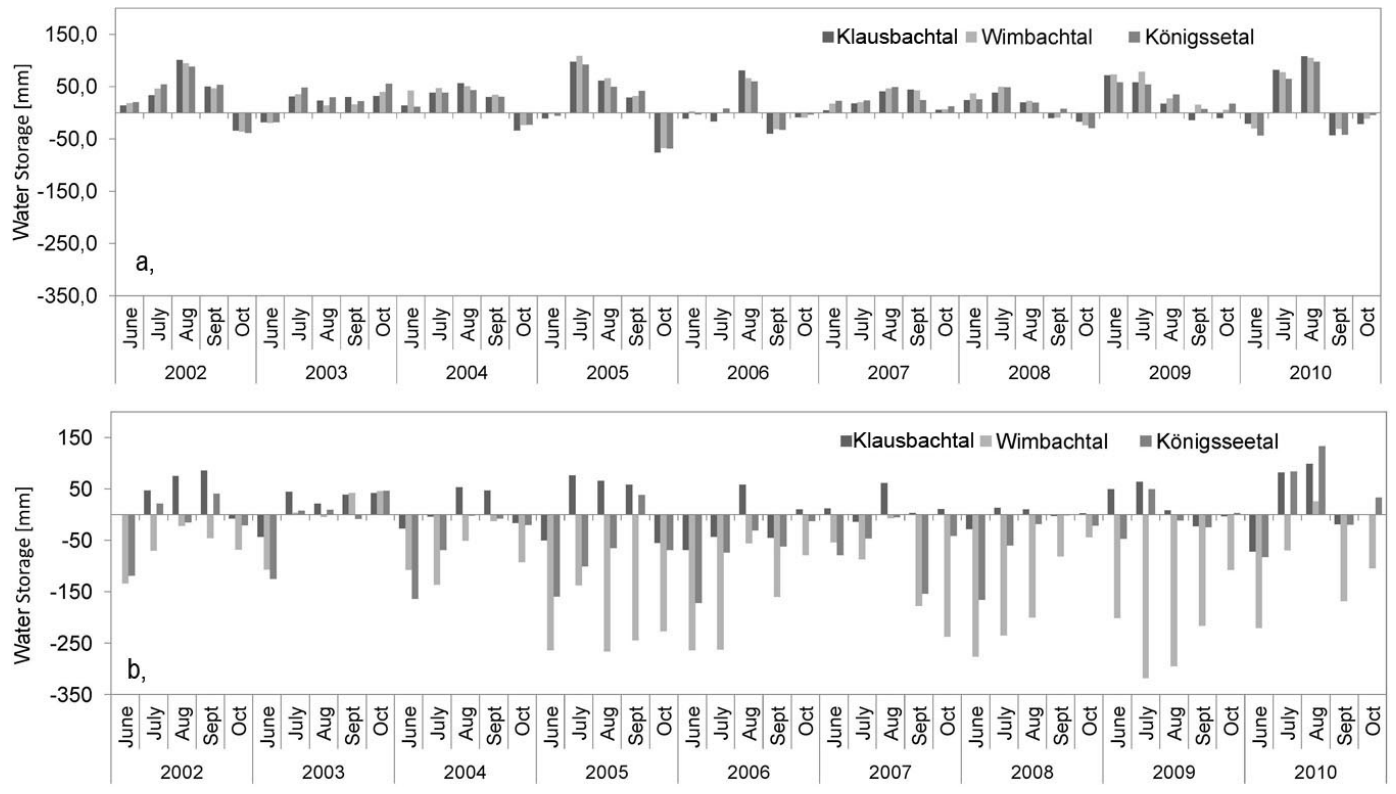

Fig. 8. (a) Comparison of the water storage $\left(S_{\text {mod }}\right)$ derived from results of hydrological model runoff before ANN correction. Monthly sums June-October 2002-2011. Subbasins Klausbachtal, Wimbachtal, Königsseetal. (b) Comparison of the water storage $\left(S_{\text {obs }}\right.$ real $)$ derived from measured runoff. Monthly sums June-October 2002-2011. Subbasins Klausbachtal, Wimbachtal, Königsseetal.

$-20 \mathrm{~mm}$ ) indicating more river runoff than incoming precipitation and consequently water inflow into the system. Figure 9 shows monthly sums for measured runoff and hydrological model runoff for summer months in the years 2001 to 2011. Runoff is mostly highly underestimated by the hydrological model in springtime but also in summer months where no snow melt is present. Especially year 2010 is different compared to the other years as there is a good performance of the distributed model considering monthly sums of runoff. Modeled runoff underestimates measured runoff. Figure 10 shows the annual dynamic of main water balance components for each hydrological year within the study 


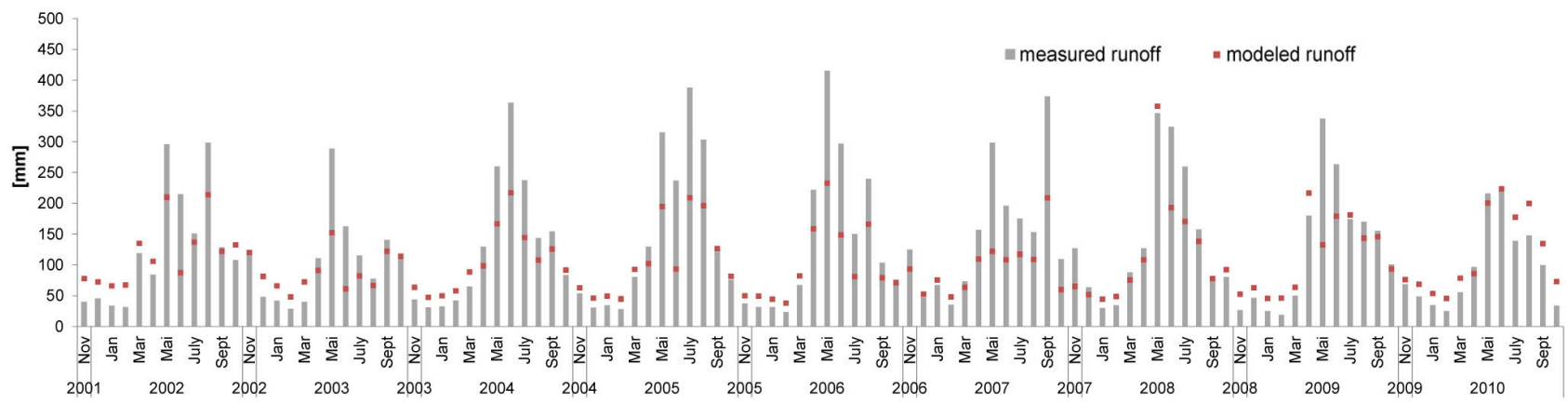

Fig. 9. Monthly sums of measured runoff and modeled runoff in subbasin Königsseetal before ANN correction -for years 2001 to 2010.

period for subbasin Königssetal. Figure 10a and b show the sum of snowmelt and rain and snowmelt only. In November, snowmelt and rain are hydrological input into the system, from February to June snowmelt is dominant, and from June to October it is mainly rainfall that contributes to the water balance in the subbasin. The evapotranspiration (Fig. 10c) shows an annual dynamic with a peak in July. Figure 10d shows water storage derived from the modeled runoff by the hydrological model. In winter months, storage is nearly zero, in spring values are negative due to snow melt, while in summer values are slightly positive due to soil water storage. Figure 10e shows the water storage derived from the measured runoff. In winter months, the storage is positive due to snow cover build-up. In May there is strong snow melt impact, leading to negative storage values. In summer months, storage remains negative indicating water inflow through unknown subsurface processes. We assume that underground catchment sizes differ from surface catchment sizes as they are presumed for distributed modeling, and that this is the cause of deviating water storage quantities.

\section{Artificial neural net to calculate boundary fluxes and distributed model correction}

Analysis of the mismatches indicates that there are systematic subsurface boundary fluxes that can be expressed as observed water storage. This water storage in the karst aquifer is temporally diverse and underlies many influencing processes such as precipitation income and intensity, evapotranspiration and soil water processes. These processes and their interaction are highly complex and it is not possible to physically describe them in detail within the study area. The hydrological model needs to be adapted to the special hydrological systems in the high Alpine karst environment. We developed an artificial neural network (ANN) as introduced by Herz et al. (1991) and Haykin (1999) to calculate the observed water storage (Fig. 2). ANNs are nonlinear input-output models that are able to reproduce the desired output based on a given input parameter set. It is then able to determine complex input-output relationships where physically based methods are limited. The network itself is trained by parameter adjusting and after validation available itself as tool for calculating subsurface conditions. Due to the algorithm, negative and positive water storage can be considered. Artificial neural networks have already been applied in karstic environments by Dou et al. (1997); Dixon (2005); Siou et al. (2011); Kurtulus and Razack (2010); Kunstmann et al. (2006a) to calculate spring response and stream discharge. The ANN in our study does not calculate stream or spring discharge, but the observed water storage. With this method we describe the strong heterogeneity and discontinuity of the medium. Input variables are hydrological model outputs. ANNs approaches are usually implemented using common libraries, as they are, for example, available for the Matlab ${ }^{\circledR}$ Neural Network Toolbox libraries. We present the analytical solution of the neural network to enable implementation of this method within the hydrological model source code. We want to emphasize that this new approach combines a neural network approach to calculate karst water storage with the temporal and spatial dynamic correction of a distributed physically based hydrological model. We tested several ANNs where we changed the time increment of given input and output parameters to find the best setup for monthly water balance correction of the hydrological model. Furthermore, we tested the effect of the correction based on different time increments on the resulting runoff dynamic performance.

\subsection{Artificial neural network (ANN)}

We developed and tested two layer feedforward artificial neural network (ANN) with a sigmoid function in the hidden layer, and a linear function in the output layer for the subbasin Königsseetal (Fig. 11) in six different time increments where input and output parameters were aggregated to sums of 5, 10, 15, 20, 25 and 30 day, respectively (time period 2001 to 2010). The inputs $Q_{\mathrm{S}}(t)$ (snow melt and/or rain), snow precipitation $P_{\mathrm{S}}(t)$, temperature $T(t)$ and relative humidity $\mathrm{RH}(t)$ give the observed water storage $S_{\mathrm{Obs}_{\mathrm{ANN}}}(t)$ (Eq. 4). These explanatory variables for the artificial neural net are interpolated outputs of the hydrological model to ensure that the ANN is not based on measured data. The input data were 

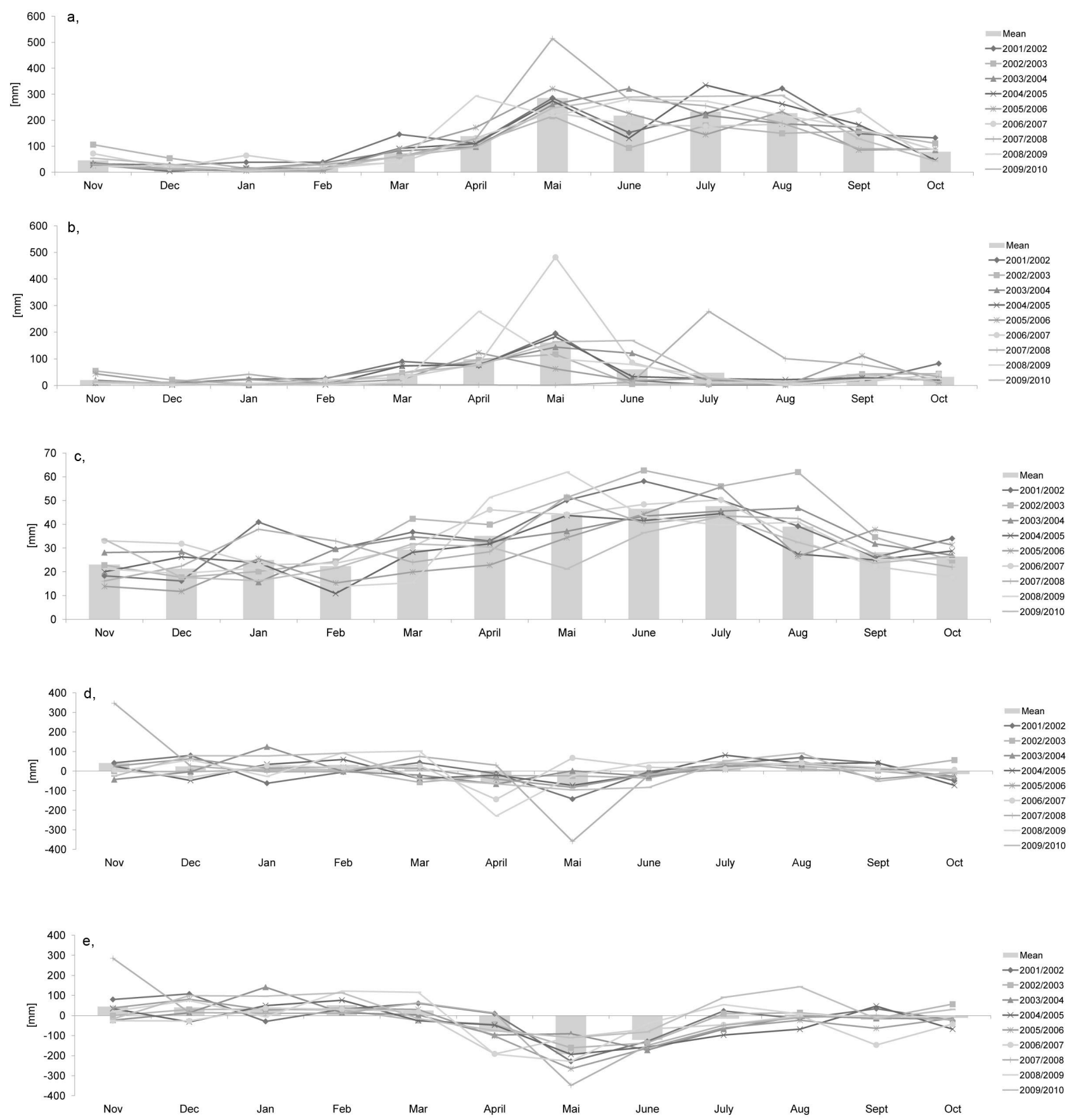

Fig. 10. Monthly sums of snowmelt + rain (a), snowmelt (b), evapotranspiration (c), water storage of the hydrological model (d) and observed water storage (e) for hydrological years 2001-2010 in subbasin Königsseetal.

calculated with hydrological model output before ANN development. During the training process and input data testing, four input variables turned out to perform best. Temperature $T(t)$ and air humidity $\mathrm{RH}(t)$ as interpolated meteorological variables to capture seasonality and air moisture; snow precipitation $P_{\mathrm{S}}(t)$ and $Q_{\mathrm{S}}(t)$ are the calculated input into the hydrological system. No sliding window is needed. Selection of the number of hidden neurons was done by an autocalibration algorithm. ANN setups are presented in Table 6 . The size of the training and validation data sets is based on the given time increment. The dataset was split up in $60 \%$ training and validation data and $40 \%$ testing data. The dataset for training and validation was split into $85 \%$ training data and $15 \%$ validation data. Training is done with a known set of input and output data and aims at finding a parameter set in such a way that the ANN can reproduce the output 
Table 4. Annual sums and mean of modeled precipitation, evapotranspiration, modeled and measured discharge -subbasins Klausbachtal, Wimbachtal and Königsseetal.

\begin{tabular}{lrrrr}
\hline & Year & Klausbachtal & Wimbachtal & Königsseetal \\
\hline Area $\left[\mathrm{km}^{2}\right]$ & & 42.79 & 35.69 & 163.54 \\
Precipitation/ & $2001 / 2002$ & $2154 / 344$ & $1983 / 344$ & $1900 / 432$ \\
evapotranspiration & $2002 / 2003$ & $1665 / 395$ & $1565 / 395$ & $1532 / 458$ \\
{$[\mathrm{~mm}]$} & $2003 / 2004$ & $1805 / 346$ & $1738 / 346$ & $1673 / 400$ \\
& $2004 / 2005$ & $1829 / 328$ & $1745 / 328$ & $1667 / 351$ \\
& $2005 / 2006$ & $1640 / 319$ & $1595 / 319$ & $1552 / 339$ \\
& $2006 / 2007$ & $1685 / 363$ & $1645 / 363$ & $1643 / 404$ \\
& $2007 / 2008$ & $1836 / 342$ & $1789 / 342$ & $1923 / 389$ \\
& $2008 / 2009$ & $1856 / 340$ & $1857 / 340$ & $1842 / 379$ \\
& $2009 / 2010$ & $1575 / 278$ & $1681 / 278$ & $1777 / 334$ \\
\hline Mean precipitation/ & & $1605 / 306$ & $1560 / 306$ & $1551 / 349$ \\
evapotranspiration [mm] & & & & \\
\hline Measured/modeled & $2001 / 2002$ & $1183 / 1654$ & $1535 / 1494$ & $1402 / 1427$ \\
runoff [mm] & $2002 / 2003$ & $1375 / 1296$ & $1872 / 1186$ & $1634 / 1077$ \\
& $2003 / 2004$ & $996 / 1418$ & $1045 / 1317$ & $1197 / 1260$ \\
& $2004 / 2005$ & $1253 / 1475$ & $1783 / 1384$ & $1596 / 1299$ \\
& $2005 / 2006$ & $1235 / 1331$ & $2622 / 1289$ & $1784 / 1201$ \\
& $2006 / 2007$ & $1259 / 1274$ & $2269 / 1220$ & $1799 / 1169$ \\
& $2007 / 2008$ & $1128 / 1402$ & $2346 / 1324$ & $1831 / 1422$ \\
& $2008 / 2009$ & $1178 / 1381$ & $2544 / 1368$ & $1597 / 1362$ \\
modeled runoff [mm] & $2009 / 2010$ & $1253 / 1313$ & $2808 / 1355$ & $1593 / 1416$ \\
\hline & & $1086 / 1254$ & $1882 / 1194$ & $1443 / 1164$ \\
& & & & \\
\hline Mean measured/ & & & &
\end{tabular}

Table 5. Minimum, maximum and mean of monthly modeled $\left(S_{\text {mod }}\right)$ water storage by the hydrological model and observed water storage $\left(S_{\text {obs }}\right)$ in subbasin Klausbachtal, Wimbachtal and Königsseetal (mm).

\begin{tabular}{lrrr}
\hline & Klausbachtal & Wimbachtal & Königsseetal \\
& $S_{\text {mod }} / S_{\text {obs }}$ & $S_{\text {mod }} / S_{\text {obs }_{\text {real }}}$ & $S_{\text {mod }} / S_{\text {obs }_{\text {real }}}$ \\
\hline Max & $265 / 271$ & $275 / 205$ & $347 / 285$ \\
Min & $-275 /-191$ & $-272 /-316$ & $-360 /-348$ \\
Mean & $4 / 21$ & $7 /-53$ & $3 /-20$ \\
\hline
\end{tabular}

data satisfactorily. In the validation, the network is prevented from overfitting. Overfitting means that the ANN learns to reproduce the noise of the data or the data pairs itself rather than trends in the data set as a whole. When beginning to train the ANN, the error for training and validation data decreases. The errors for the training set continue to decrease, after the optimal amount of training has been achieved, but validation data error increases. Model training is stopped before. The validation error increases. Table 6 shows the ANN results. Net training to obtain the parameters $a_{i}$ to $g_{i}$ was done with the Levenberg-Marquardt algorithm for which the RMSE was chosen as the objective function to be minimized (Eq. 5).

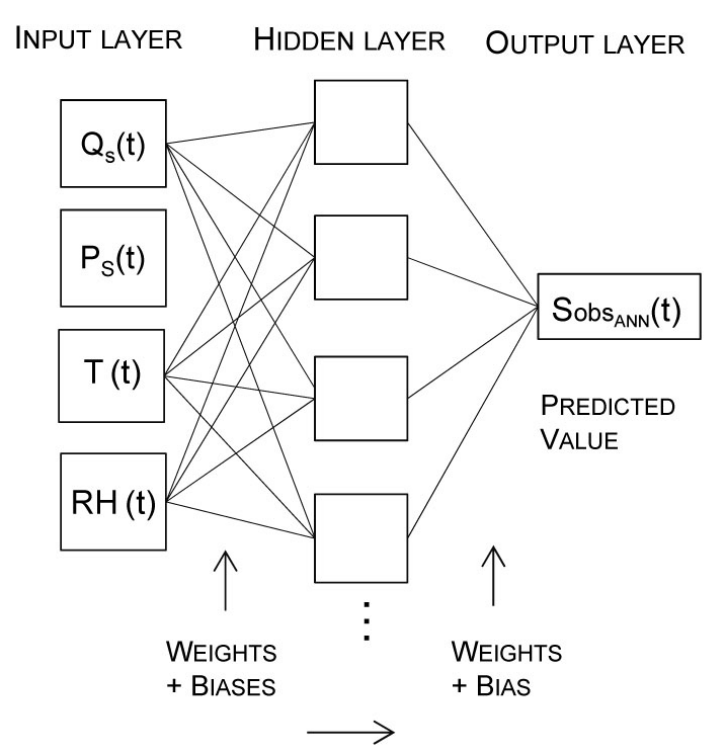

Fig. 11. Architecture artificial neural network. Input layer, hidden layer and output layer. The inputs $Q_{\mathrm{S}}(t)$ (snow melt and/or rain), snow precipitation $P_{\mathrm{S}}(t)$, temperature $T(t)$, relative humidity $\mathrm{RH}(t)$ give the observed water storage $S_{\text {obs ANN }}(t)$. 
Table 6. Artificial neural net setup and performance.

\begin{tabular}{rrrrrrllllll}
\hline TI & HN & total & Training & Validation & Testing & lin R-Square & log R-Square & Index d & linNSE & MSE & RSME \\
& & $n$ & $n$ & $n$ & $n$ & & & & & & \\
\hline 5 & 18 & 657 & 335 & 59 & 263 & 0.6 & 0.31 & 0.57 & 0.6 & 432 & 20 \\
10 & 1 & 328 & 167 & 30 & 131 & 0.39 & 0.29 & 0.38 & 0.69 & 1607 & 40 \\
15 & 3 & 219 & 111 & 20 & 88 & 0.5 & 0.31 & 0.52 & 0.71 & 2369 & 48 \\
20 & 6 & 164 & 83 & 15 & 66 & 0.56 & 0.33 & 0.5 & 0.44 & 3539 & 56 \\
25 & 14 & 131 & 67 & 12 & 52 & 0.58 & 0.35 & 0.56 & 0.9 & 4712 & 57 \\
30 & 6 & 109 & 55 & 10 & 44 & 0.56 & 0.33 & 0.54 & 0.82 & 1707 & 84 \\
\hline
\end{tabular}

linear R-Square, logartihtmic R-Square, Index d, linear NSE, MSE and RSME for the six time increments $(n=$ number of datasets; HN = Hidden Nodes; TI = Time increments).

$S_{\mathrm{obs}_{\mathrm{ANN}}}(t)=a_{i}+\sum_{i=1}^{n} \frac{b_{i}}{1+e^{c_{i}+d_{i} Q_{\mathrm{S}}(t)+e_{i} P_{\mathrm{S}}(t)+f_{i} T(t)+g_{i} \mathrm{RH}(t)}}$

$\mathrm{RMSE}=\sqrt{\frac{1}{n} \sum_{i=1}^{n}\left(S_{\mathrm{obs}_{\mathrm{ANN}}}(t)-S_{\mathrm{obs}_{\mathrm{real}}}(t)\right)^{2}}$.

During pre- and postprocessing for the tansig transfer function net input and output were normalized from $r_{\min }=-1$ to $r_{\max }=1$ (Eq. 6) where $x_{\mathrm{s}}$ is the scaled output and $x_{t}$ is the value of the time series at the given time increment. The output of the ANN is then backtransformed using the Eq. (7):

$x_{\mathrm{s}}(t)=\left(r_{\max }-r_{\min }\right) \frac{x_{t}-x_{\min }}{x_{\max }-x_{\min }}+r_{\min }$

$x_{t}=\left(x_{S}(t)+1\right)\left(x_{\max }-x_{\min }\right) / 2+x_{\min }$.

\section{Performance evaluation - ANN}

We show results of the ANNs with different time aggregations each the test period. Table 6 shows R-Square, Index d, NSE, MSE and RSME for each ANN Setup. Best results were achieved with a 5-day time increment $\left(r^{2}=0.60\right)$ (Fig. 12), whereby the NSE $=0.6$ and the RMSE $=20$. Networks with 20, 25 and 30-day increments also show good results and their performance is very similar. Figure 13 shows the performance of the ANN for the entire time increment. None of the tested ANN setups were able to capture the positive storage value at the beginning of the time series. Furthermore, the positive water storage in 2010 could not be reproduced. The resulting storage series were reproduced satisfactorily. Dynamics and quantities of the water storage were calculated appropriately for the ANNs with larger time increments. Since the ANN with a 10-day increment shows the lowest correlation, it was not implemented as boundary flux in the hydrological model. Table 7 shows the weights and biases derived by the training process for the ANN with a 20-day time increment which shows the best results in hydrological model correction.
Table 7. Weights and biases ANN. 20-day time increment.

\begin{tabular}{lrrrrr}
\hline$b_{i}$ & $c_{i}$ & $d_{i}$ & $e_{i}$ & $f_{i}$ & $g_{i}$ \\
\hline 0.04 & -6.84 & -6.67 & -5.03 & -1.18 & 0.90 \\
0.58 & 3.30 & -4.43 & 1.57 & 0.89 & -2.03 \\
0.71 & 4.32 & -3.93 & -0.65 & -4.18 & 2.53 \\
0.59 & -2.03 & -2.66 & 3.04 & 7.18 & -5.85 \\
0.39 & 1.97 & 3.57 & -1.13 & -0.72 & 5.53 \\
0.14 & 5.39 & -7.44 & 1.24 & 2.10 & 3.84 \\
\hline
\end{tabular}

$b_{i}=$ weight hidden layer to output. $d_{i}, e_{i}, f_{i}=$ weights layer 1 to hidden layer. $c_{i}=$ bias layer 1 to hidden layer. $a_{i}=-0.54$ ( bias hidden layer to output).

\subsection{Distributed model correction: implementation of boundary flux in the saturated zone}

The ANNs reproduce the missing water quantities within the subbasin Königsseer Ache at different time increments. The missing water quantities are expressed as water storage, which is the difference of incoming effective precipitation minus measured runoff. We used the outcomes of the artificial neural network as a basis for the constant boundary flux into the hydrological model (Fig. 2). We implemented results of the ANNs for all increments in the hydrological model to analyze which increment performs best when looking at the water balance and runoff performance. During correcting, one has to take into account the water storage already calculated by the hydrological model, which is the difference of effective precipitation minus modeled runoff. Therefore, the given sum of observed water storage simulated by each of the neural networks was subtracted from the modeled water storage already calculated for the investigated period (Eq. 8). Next, this difference was converted into a time series, where influx or outflux values switched according to the time increment. For example, for the ANN with a 5-day increment, the in- or outflux value changes every 5 days. The values of the time series are automatically written into a boundary grid in WaSiM-ETH at a given extent. The difference was implemented as a continuous boundary flux $Q_{\text {bound }}(t)$ in $\mathrm{m} \mathrm{s}^{-1}$ for time increment in the saturated zone at a given area in 

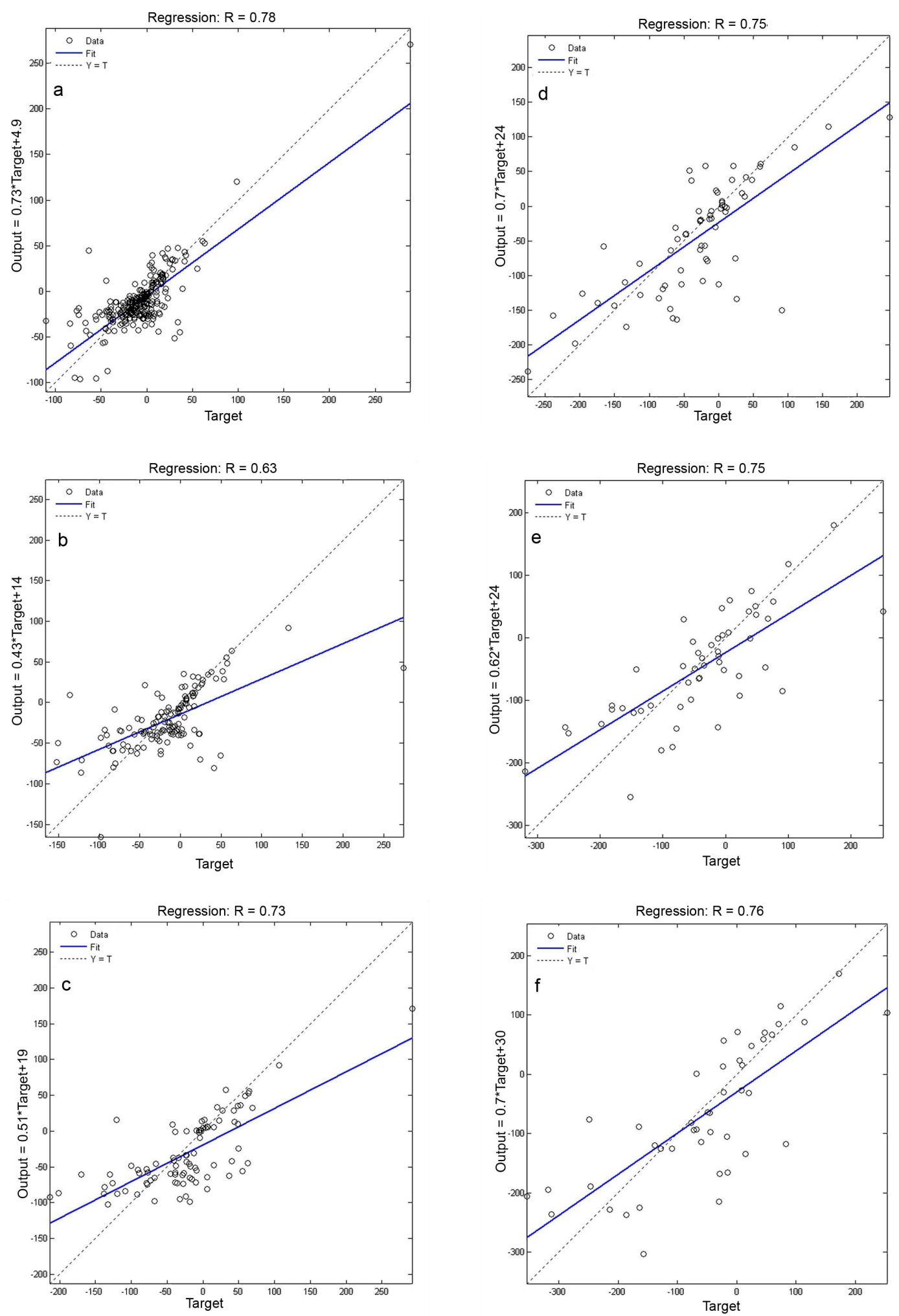

Fig. 12. Performance ANN - Test period. Correlation diagram between simulated monthly observed water storage by the ANN (output) vs. observed water storages $(\operatorname{target})-(\mathbf{a})=5$-day, $(\mathbf{b})=10$-day, $(\mathbf{c})=15$-day, $(\mathbf{d})=20$-day, $(\mathbf{e})=25$-day and $(\mathbf{f})=30$-day time increment. 

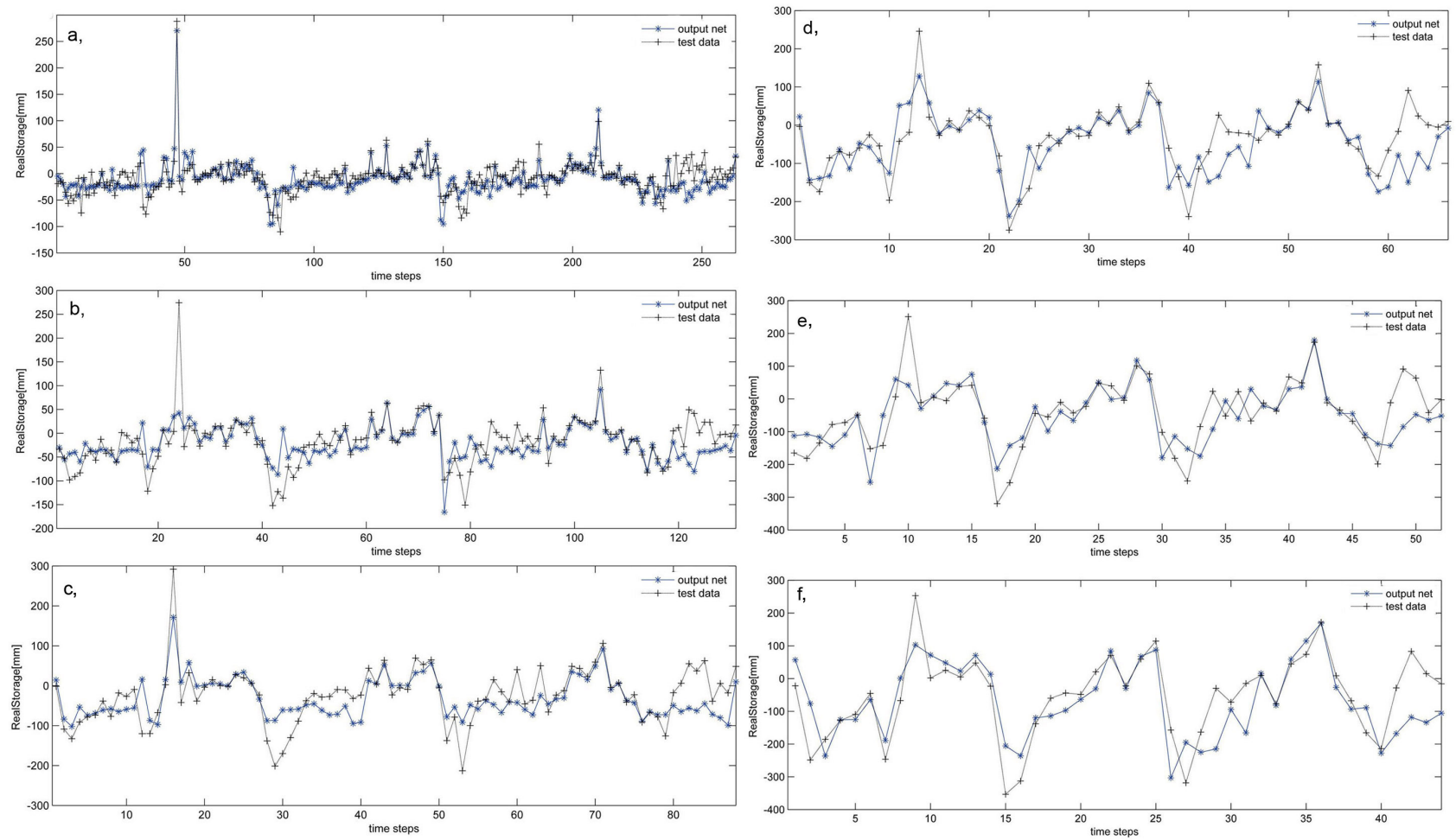

Fig. 13. Comparison of observed water storage (test data) and observed water storage simulated by the ANN (output net) in monthly sums. Test period of the neural net in subbasin Königsseetal - (a) $=5$-day, $(\mathbf{b})=10$-day, $(\mathbf{c})=15$-day, $(\mathbf{d})=20$-day, $(\mathbf{e})=25$-day, $(\mathbf{f})=30$-day increment.

the southern border of the subbasin. Influx is also possible at given influx point locations, but influx at a given area within the subbasin showed better results. During the model run, the influx was defined in an external table where the values for the influx are listed for each time step. Therefore, the hydrological model was constantly corrected during the model run. The correction was subsequently considered in consecutive modules of the hydrological model and finally routed to river outlets.

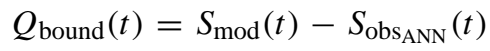

This method is not a bias correction of modeled runoff at the outlet point, but an inflow within the groundwater model, which the model accounts for and is considered in the following modeling process. The inflow size can vary from one grid cell to the whole subbasin area. We implemented a boundary flux based on the results of the test period of each of the neural net from March 2007 to October 2010.

\section{Results and discussion}

In this study, we were able to demonstrate the limitations of a hydrological model in high Alpine terrain with massive carbonate aquifers. We were able to quantify systematic model mismatch at subbasin scale and point out hydrological processes within these heterogeneous catchments that deviate from common model assumptions (Darcy Flow, porous media conditions). To enable distributed hydrologcial modeling within these catchments, which are the origin of lowland river runoff quantities and dynamics, we developed a method to describe and account for the missing water quantities. Analyses of given station data, interpolation methods and the effects of precipitation correction showed that unrealistic precipitation assumptions were not the case and could therefore be suspended as the main reason for the model mismatch. Therefore, we concluded unknown subsurface boundary fluxes to be the cause for the uneven observed water balance for the given subbasins. Or, in other words, due to underground fluxes, the real catchment size for river gauges differs from the size calculated by the hydrological model. By using porous condition parametrization, the model is unable to account for extreme differences in hydrological system at catchment scale, resulting in consistent model mismatch. Analysis of modeled runoff from 2001 to 2010 showed that it underestimates observed runoff, pointing to deviations during summer months (Fig. 9). The hydrological model underestimates river runoff in the given subbasin from April to October 2007, from June to September 2008 and from June to October 2009.

Underestimation also occurs during the summer months when snow melt is not present. Figure 14 shows the results 

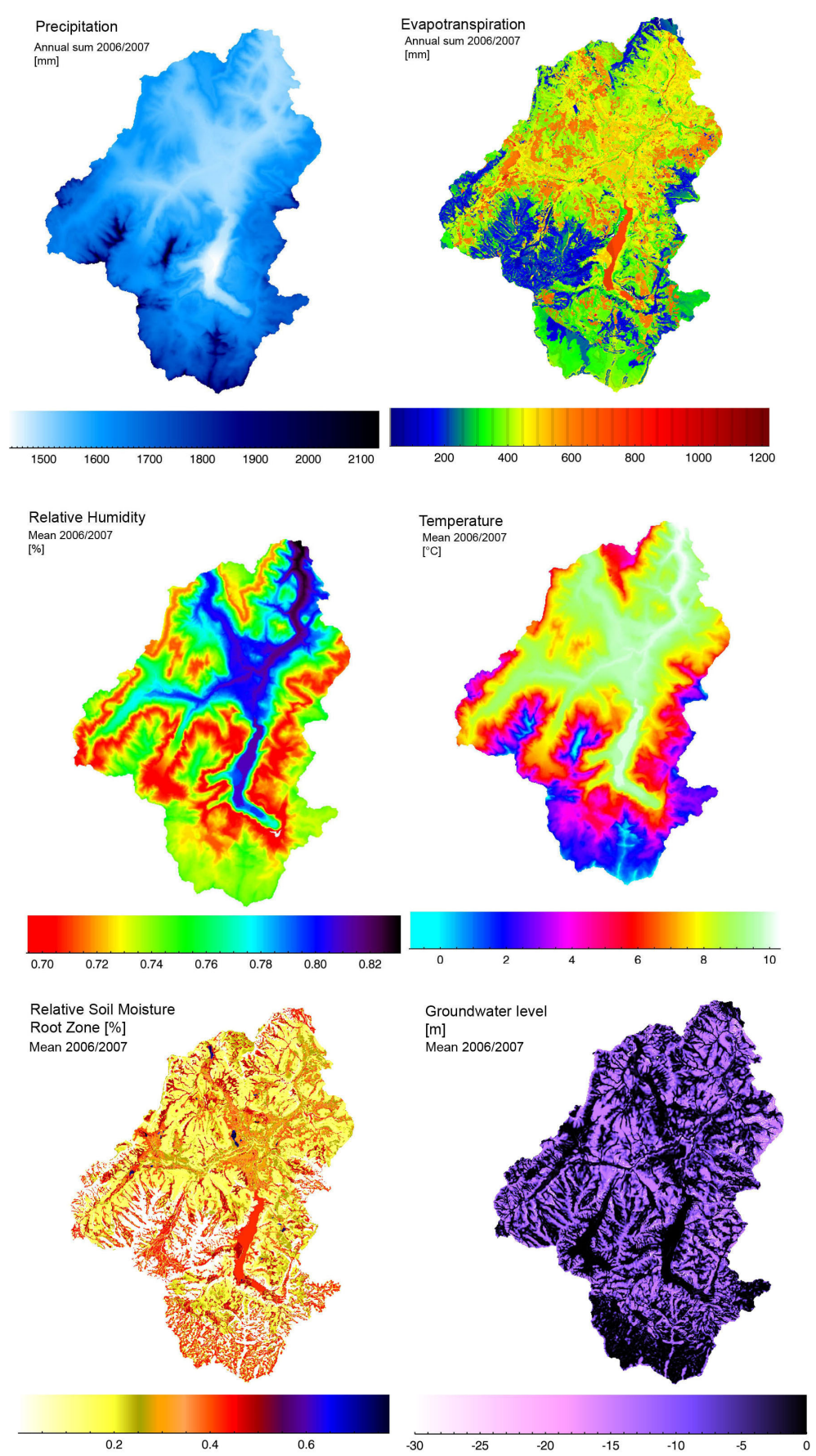

Fig. 14. Spatial water balance results of the hydrological model (before model correction). Precipitation and evapotranspiration, relative humidity, temperature, relative soil moisture and groundwater level.

of the hydrological model for the hydrological year 20062007. It is evident that the grid-based approach provides detailed information on the heterogeneous Alpine catchment. The annual sum of precipitation ranges from $1300 \mathrm{~mm}$ in the valleys to over $2100 \mathrm{~mm}$ in mountainous regions. Actual evapotranspiration is calculated to over $1400 \mathrm{~mm}$ at extreme locations and shows a mean value of $396 \mathrm{~mm}$ for the area.
Relative humidity ranges from $70 \%$ to over $82 \%$. Mean annual temperature is from $10^{\circ} \mathrm{C}$ in valleys to $-2{ }^{\circ} \mathrm{C}$ at elevated regions. The mean groundwater level in the region in the year 2006-2007 is presented. Based on the assumed soil layers, which had to be in the given range of the hydrological model, groundwater reaches the surface in valley regions, because steep gradients lead to increased flow in hill slopes. 
Table 8. Performance of the hydrological model correction 1 March 2007-31 October 2008 and 1 March 2007-31 October 2010. Values are linear and logarithmic Nash Sutcliffe efficiencies.

\begin{tabular}{|c|c|c|c|c|c|c|c|}
\hline & \multirow[b]{2}{*}{$\begin{array}{l}\text { Time } \\
\text { increment }\end{array}$} & \multicolumn{3}{|c|}{1 March 2007-31 October 2008} & \multicolumn{3}{|c|}{1 March 2007-31 October 2010} \\
\hline & & Königsseetal & $\begin{array}{r}\text { Berchtesgadener } \\
\text { Ache }\end{array}$ & St. Leonhard & Königsseetal & $\begin{array}{l}\text { Berchtesgadener } \\
\text { Ache }\end{array}$ & St. Leonhard \\
\hline $\operatorname{lin}$ & no influx & 0.48 & 0.22 & 0.57 & 0.53 & 0.33 & 0.56 \\
\hline \multirow[t]{5}{*}{ NSE } & 5 & 0.46 & 0.4 & 0.6 & 0.28 & 0.5 & 0.57 \\
\hline & 15 & 0.48 & 0.39 & 0.59 & 0.35 & 0.48 & 0.56 \\
\hline & 20 & 0.57 & 0.49 & 0.66 & 0.34 & 0.55 & 0.61 \\
\hline & 25 & 0.4 & 0.43 & 0.6 & 0.38 & 0.5 & 0.58 \\
\hline & 30 & 0.46 & 0.37 & 0.59 & 0.31 & 0.49 & 0.57 \\
\hline $\log$ & no influx & 0.56 & -0.61 & 0.67 & 0.6 & 0.06 & 0.51 \\
\hline \multirow[t]{5}{*}{ NSE } & 5 & 0.35 & -0.15 & 0.31 & 0.24 & 0.37 & 0.2 \\
\hline & 15 & 0.34 & -0.02 & 0.23 & 0.18 & 0.42 & 0.15 \\
\hline & 20 & 0.46 & 0.05 & 0.4 & 0.31 & 0.48 & 0.27 \\
\hline & 25 & 0.24 & -0.04 & 0.22 & 0.28 & 0.41 & 0.25 \\
\hline & 30 & 0.29 & -0.11 & 0.27 & 0.19 & 0.42 & 0.22 \\
\hline
\end{tabular}

Soil moisture in the root zone ranges from zero to almost $100 \%$. The massive karst aquifer itself and the location of all conduits and subsurface flow channels remain a black box. However, based on tracer experiments and spring locations we were able to synthesize that the main underground flow direction tends to be north, which corresponds to the results of the hydrological model mismatch (Kraller et al., 2011). We assume the missing or additional water quantities in the high Alpine subbasins are caused by boundary fluxes from outside the study area. No internal boundary fluxes (e.g. from the Wimbachtal to the Königsseetal) are considered during the development of this new method. Since we are unable to quantify each underground flux in the study area, and especially the dynamics throughout a hydrological year, we chose a statistical method to capture unknown underground flow processes at subbasin catchment scale on various temporal time increments. By developing the artificial neural net, we were able to reproduce monthly storage deviations. A two layer feedforward backpropagation network was developed with a sigmoid function in the hidden layer and a linear function in the output layer with varying number of neurons in the hidden layer. The neural networks give satisfactory representation of observed water storage. For each of the ANNs, we implemented a constant boundary flux in $\mathrm{m} / \mathrm{s}$ for each time increment in the saturated zone module of the hydrological model for subbasin Königsseetal based on the results of the ANN for the years 2007 to 2010. The influx was then involved in the consecutive modules during model run. Performance of the hydrological model improved with implementation of the constant boundary flux (Eq. 8). We analyzed hydrological model performance in the corrected subbasin Königsseetal, but also the effects of the correction on downstream subbasins Berchtesgadener Ache and St. Leonhard. Figure 15 a to c shows monthly sums of measured runoff, modeled runoff and modeled runoff after implementing the boundary flux from 2007 to 2010 for all the time increments. In 2007 and 2008, the modeled runoff improves for most of the time aggregations, however there is slight overestimation in July and August 2007. In 2009 and 2010, runoff is overestimated in the summer months. The reason for this is that the artificial neural network is trained to extreme inflow events in late summer as it is the case for all years before 2009 . In 2009 and 2010, there is no such a system behavior and the artificial neural network is therefore overestimates the influx, leading to overestimated runoff.

The ANN and the influx is perform very well during winter and spring time, the hydrology of the processes within the watershed does not seem to be so variable during that time. The approach underlines the extreme heterogeneity of the hydrologic processes taking place during summer months in a karstified watershed. Best performance in the hydrological model correction is shown by the artificial neural network with 20-day time increment. When analyzing the period from 1 March 2007 to 31 October 2010 Linear Nash Sutcliffe efficiency increases from 0.48 to 0.57 in subbasin Königsseetal, from 0.22 to 0.49 in subbasin Berchtesgadener Ache and from 0.57 to 0.66 in subbasin St. Leonhard (Table 8). In subbasin Königsseetal no other time increment results in modeled runoff improvement. However, in Berchtesgadener Ache and St. Leonhard all time increments improved modeled results (linear NSE). Looking at the logarthmic NSE, only subbasin Berchtesgadener Ache shows improvements. When looking at the whole correction period for the 20-day time increment from 1 March 2007 to 31 October 2010, NSE only increases in subbasin Berchtesgadener Ache (0.33 to $0.55)$ and St. Leonhard (0.56 to 0.61$)$. No improvement could be achieved in subbasin Königseetal. The reason for this is overestimation of storage of the ANN in years 2009 and 

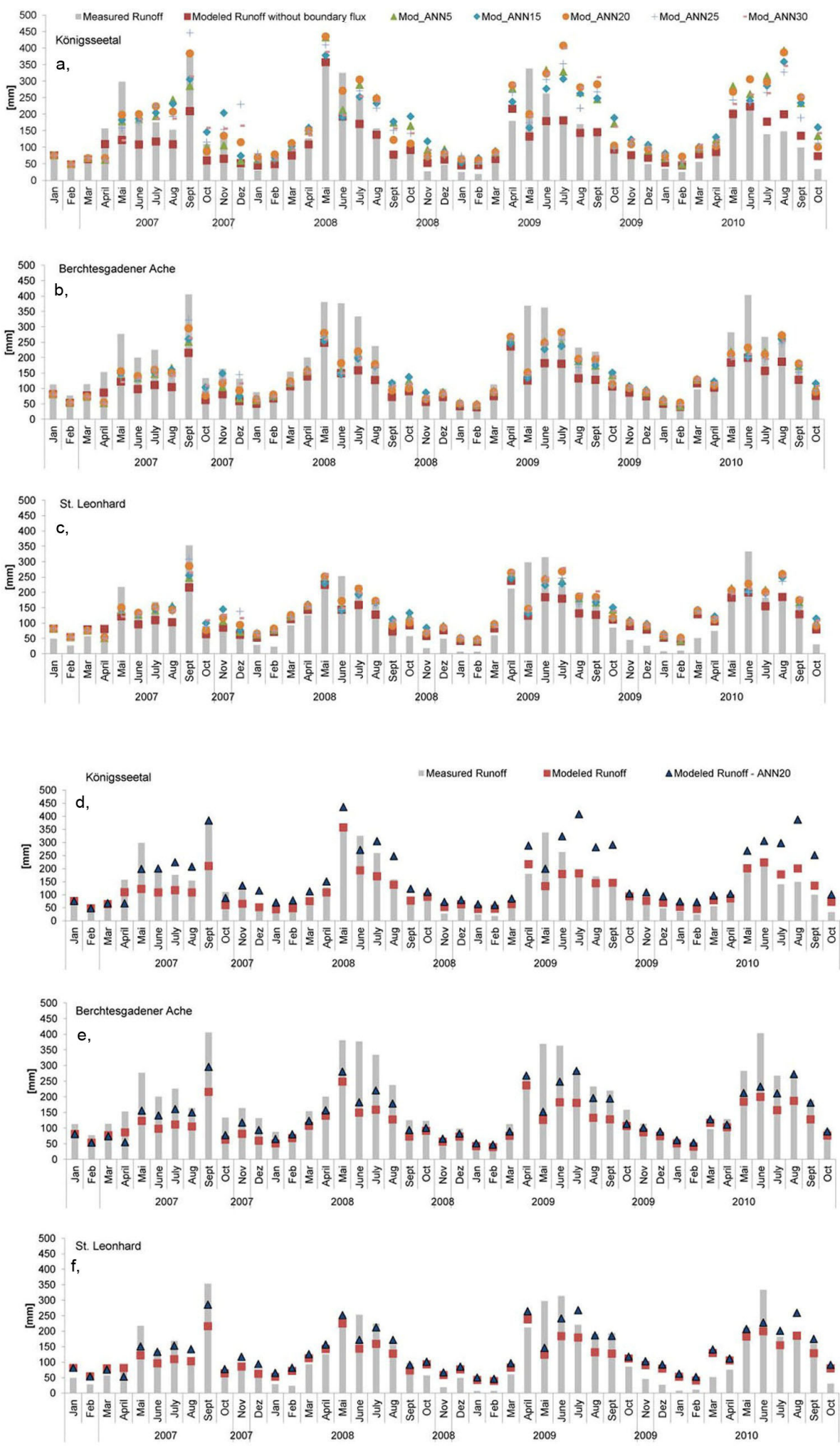

Fig. 15. Monthly sums of measured runoff and hydrological model runoff with and without implemented boundary flux from June to October for years 2007-2010 for subbasin Königsseetal, Berchtesgadener Ache and St. Leonhard. (a), (b), (c): Results of influxes of all time increments in subbasin Königsseetal, Berchtesgadener Ache and St. Leonhard. Mod-ANN5=5 days, Mod-ANN15=15 days, ModANN20 $=20$ days, Mod-ANN25 = 25 days, Mod-ANN30 = 30 days. (d), (e), (f): Results for the ANN with 20-day time increment, which showed best performance in the hydrological model correction. 


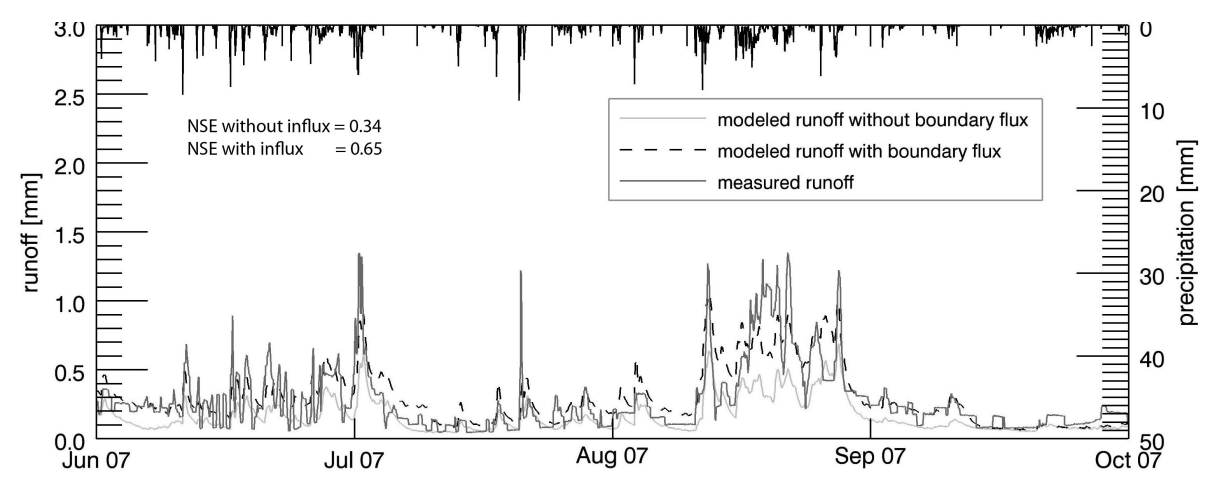

Fig. 16. Measured runoff, modeled runoff and modeled runoff with implemented boundary flux (20-day time increment) for June to October 2007 for subbasin Königsseetal. Linear Nash Sutcliffe Efficiency shows model performance from June to October 2007.

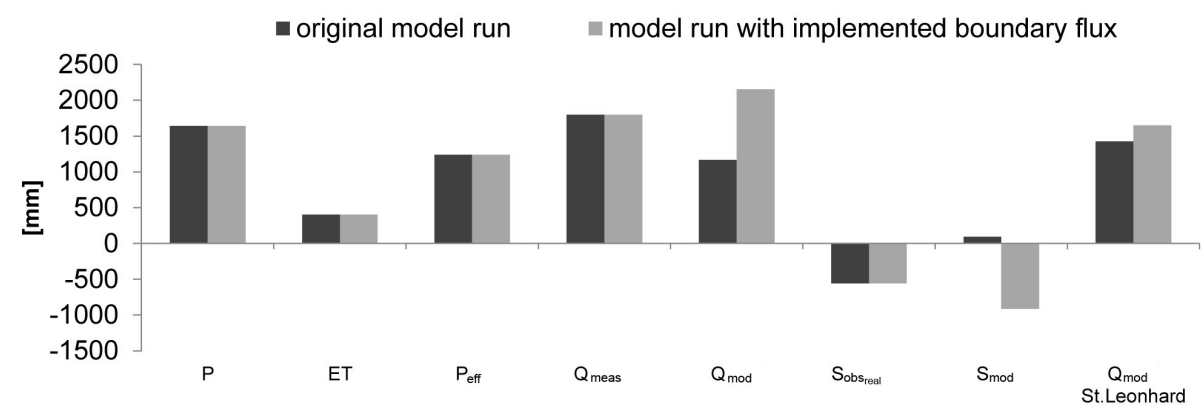

Fig. 17. Water balance components for subbasin Königsseetal and modeled runoff for St. Leonhard - annual sums 2007. Results for original model run and model run with implemented boundary flux $\left(P=\right.$ precipitation, ET $=$ evapotranspiration; $P_{\text {eff }}=$ effective precipitation, $Q_{\text {obs }}=$ measured runoff, $Q_{\text {mod }}=$ modeled runoff, $S_{\text {obs }}=$ observed storage, $S_{\text {mod }}=$ modeled storage ).

2010 is leading to an overestimation of runoff. In the shorter time period there is an improvement for subbasin Berchtesgadener Ache for all time increments (linear NSE and logarithmic NSE) and a slight improvement for St. Leonhard for all time increments (linear NSE). It is important to note, that at that position runoff performance in downstream subbasins Berchtesgadener Ache and St. Leonhard is also influenced by the runoff dynamics of other subbasins (e.g. Wimbachtal, Klausbachtal, Ramsauer Ache) and, of course, that the model correction in subbasin Königsseetal alone cannot improve model results for these river gauges. Here we show the effect on downstream subbasins of hydrological model correction in a head subbasin. The lower graphs of Fig. $15 \mathrm{~d}$ to e show monthly sums of measured runoff, modeled runoff and modeled runoff with boundary flux for the network with 20-day aggregation for subbasin Königsseetal, Berchtesgadener Ache and St. Leonhard. Modeling is improved at both gauges. Since there is also an underestimation of runoff in the subbasin Wimbachtal which effects discharge at gauge Berchtesgadener Ache and St.Leonhard, the results are only slightly better. Application of the method in the Wimbachtal and the Königsseetal would lead to a greater improvement. Figure 16 shows measured runoff, modeled runoff and modeled runoff with implemented boundary flux for June to October 2007. The correction improves runoff in late June and early July, but only slightly influences winter periods. During peak flow between August and September, the correction shows good performance at two minor peaks and runoff is increased. However, it is still sligthly underestimated in the main peak. Reproduction of the monthly sum of September is very satisfactory (Fig. 15).

Figure 17 shows the main components of the annual water balance of 2007 in subbasin Königsseetal before and after hydrological model correction. Since the inflow takes place in the saturated zone module, the annual sums of precipitation $(1643 \mathrm{~mm})$, evapotranspiration $(404 \mathrm{~mm})$, effective precipitation $(1249 \mathrm{~mm})$ and observed water storage $(-550 \mathrm{~mm})$ calculated are the same before and after boundary flux. Observed water storage was negative in the annual balance, because subsurface water inflow takes place throughout subbasin borders (derived by the DEM). In the original model run, the modeled runoff $(1169 \mathrm{~mm})$ underestimated measured runoff. After implementing the boundary flux, modeled runoff is increased to $2153 \mathrm{~mm}$. Originally, modeled water storage was minimal $(80 \mathrm{~mm})$, because the hydrological model even calculates annual water balances internally. By correcting the hydrological model with the constant inflow on a monthly basis, annual modeled water storage resulted in $-914 \mathrm{~mm}$ and improved reproduction of observed water storage. At river gauge St. Leonhard, which is the outlet of 
the whole catchment, modeled runoff also increases, showing improved distributed hydrological modeling for the overall study area. Storage capacities are reached within the saturated zone in the given soil layers, and water excess is given for the unsaturated zone. Figure 18 presents runoff components of modeled runoff in year 2007 before and after implementation of the boundary flux. In the original model run, the rates calculated for directflow and baseflow were almost equal, whereas interflow was the main contributor to modeled runoff. After implementing the boundary flux, directflow increased most, whereas baseflow remained almost unchanged and interflow decreases. As the groundwater module and unsaturated zone module in the hydrological model are coupled bidirectionally, increased baseflow is leading to saturation in the soil and directflow is produced due to saturation excess. ANNs have been used previously in hydrological studies, but mainly to predict and calculate the discharge of a given river course or spring rather than deviating storage conditions. Our new method describes the ANN analytically and enables to calculate unknown storage processes in complex hydrogeological environments in different time increments. With this method, the hydrological model reproduces storage conditions more realistically in high Alpine karst terrain, which leads to a more realistic runoff at catchment scale. The challenge of this new method was to find an adequate combination of artificial neural network time increment and hydrological model correction, because it was not clear wether best ANN setup corresponds to best hydrological model performance after correction. The ANN is a statistical-empirical method that is able to reproduce static conditions, in our case static water storage in the given time aggregation. However, the aim of hydrological model correction is to correct the overestimated water balance first, followed next by the dynamics of the overestimated water quantities. What we found is that the method increases model performance on a monthly time basis for hydrological years, where the runoff is strongly underestimated in summertime.

The ANN is trained to reproduce such storage effects. Without such a system behavior, the ANN tends to overestimate such influxes and consequently the hydrological model overestimates runoff. Looking at the runoff dynamics after hydrological model correction, runoff curves show, that the method is limited to correct adequately for every peak flow in high Alpine subbasin Königsseetal. Although correction significantly improved model results in monthly sums, the peak flow is not perfectly matched. The method is developed to correct for monthly sums and not for hourly data. However, runoff dynamics is based on hourly data. We assume that, in reality, there are fast flow components in the unsaturated zone (karst channels) that are directly routed to the receiving water after emerging at spring locations. Steep gradients and orography intensify fast flowing water within the watershed. These fast flowing processes can be attributed to flow velocities of interflow of direct flow although happening in the unsaturated or saturated zone and possibly being
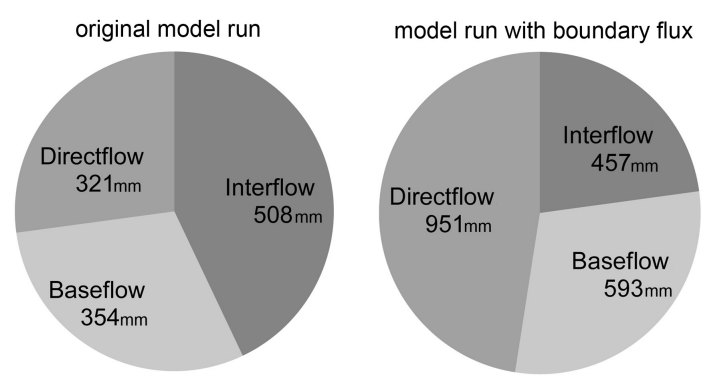

Fig. 18. Components of modeled runoff. Subbasin Königsseetal annual sums [mm] 2007. Results for original model run and model run with implemented boundary flux.

the reason for the peak flow events. The method corrects water fluxes in the groundwater zone. Thus, the baseflow is corrected but this does not always improve modeled peak flow because the algorithm of the groundwater module remains unchanged and the influx is converted to groundwater flow based on Darcy flow. If saturation of the soil is reached, excess water is converted to direct flow. However, this does not lead to peak discharge in all cases. Regarding the runoff dynamics of the hydrological model the developed method works well for downstream subbasins, where slower flow processes are more dominant. We found that the model performance in subbasins Berchtesgadener Ache and St. Leonhard increased for all the years and almost all time increments. Missing water in these downstream subbasins is mainly caused by baseflow. The baseflow is increased due to the influx and hydrological model performance therefore increases. In this study, we were able to show the limitations of a distributed hydrological model in high Alpine terrain with massive carbonate aquifers. We were able to quantify systematic model mismatch at subbasin scale and point out hydrological processes within these heterogeneous catchments that deviate from common model assumptions (Darcy Flow, Porous Media Conditions). To enable hydrological modeling within these catchments, which are the origin of lowland river runoff quantities and dynamics, we developed a method to describe and account for the missing water quantities.

\section{Summary and conclusions}

We implemented a distributed hydrological water balance model in the watershed of the river Berchtesgadener Ache. The model area was derived during preprocessing by surface water divides. Since the model area is situated in high Alpine karst, we expect groundwater basin sizes to differ from surface basin sizes. This was also indicated by Kraller et al. (2011), who synthesized northerly subsurface water flow direction. Each of the three neighboring high Alpine head subbasins is unique in its hydrology, indicated by huge runoff deviations when comparing the annual sums of measured discharge. Distributed hydrological modeling resulted 
in systematic model mismatch in these neighboring high Alpine subbasins. Model mismatch is concluded to be a consequence of deviations in water storage in reality and the hydrological model. We have demonstrated a novel method to account for boundary fluxes of karst aquifers within the hydrological model on a monthly time basis. An artificial neural network is able to reproduce missing storage quantities and the consecutive model correction could significantly improve modeled runoff in subbasin Königsseetal. Further studies should be conducted to investigate whether this method can be successfully transferred to other subbasins within the area or other watersheds in karst terrain. Furthermore, in a next step boundary fluxes within neighboring subbasins should also be considered.

Acknowledgements. This project was initiated and financed by the Authority of the Berchtesgaden National Park. The authors gratefully acknowledge the continuous support of Michael Vogel, head of the Berchtesgaden National Park and Helmut Franz, research coordinator of the Berchtesgaden Nationalpark. Furthermore, we want to thank Günther Kus for helpful comments. Special thanks go to involved institutes and authorities for data supply and to Severin Kaspar for motivated neural network discussions. We gratefully acknowledge the detailed comments of the reviewer Jörg Schulla, the second anonymous reviewer and the editor. We also thank the European Environment Agency (EEA) for providing Corine Land Cover Data (CLC) for land use classification.

Edited by: A. Butturini

\section{References}

Attkinson, T.: Diffuse Flow and Conduit Flow in Limestone Terrain in the Mendip Hills, Sommerset (Great Britain), J. Hydrol., 35, 93-110, 1977.

Bakalowicz, M.: Karst groundwater: a challenge for new resources, Hydrogeol. J., 13, 148-160, 2005.

Barthel, R.: A indicator approach to assessing and predicting the quantitative state of groundwater bodies on the regional scale with a special focus on the impacts of climate change, Hydrogeol. J., 19, 525-546, 2011.

BGRSGD: HUEK200, Hydrogeologische Uebersichtskarte von Deutschland, Oberer Grundwasserleiter, Tech. rep., Bundesanstalt fuer Geowissenschaften und Rohstoffe, Staatliche Geologische Dienste der BRD, 2007.

Birk, S., Liedl, R., and Sauter, M.: Identification of localised recharge and donuit flow by combined analysis of hydraulic and physico-chemical spring responses (Urenbrunnen, SW Germany), J. Hydrol., 286, 179-193, 2004.

Bonacci, O.: Karst springs hydrographs ans indicators of karst aquifers., Hydrolog. Sci. J., 38, 51-62, 2004.

Brutsaert, W.: Evaporation into the atmosphere, Kluwer Academic Publishers, 1982.

Caroll, R., Pohll, G., Earman, S., and Hershey, R.: A comparison of groundwater fluxes computed with MODFLOW and a mixing model using deuterium: Application to the eastern Nevada Test Site and vicinity, J. Hydrol., 361, 371-385, 2008.
Dixon, B.: Application of neuro-fuzzy techniques in predicting ground-water vulnerability: a GIS-based sensitivity analysis, J. Hydrol., 309, 17-38, 2005.

Dou, C., Wold, W., Dahab, M., and Bogardi, I.: Transient GroundWater Flow Simulation Using a Fuzzy Set Approach, Ground Water, 35, 205-215, 1997.

EEA: Regional climate change and adaption, The Alps facing the challenge of changing water resources, EEA Report, No. 8/2009, Tech. rep., EEA, 2007.

Einsiedl, F.: Flow system dynamics and water storage of a fissuredporous karst aquifer characterized by artificial and environmental tracers, J. Hydrol., 312, 312-321, 2005.

Fischer, K.: Geomorphologie der Berchtesgadener Alpen Forschungsbericht 50, Nationalparkverwaltung Berchtesgaden, 2005.

Ford, D.: Perspectives in karst hydrogeology and cavern genesis, Speleogen. Evol. Karst Aquif., 1, 1-12, 2003.

Geyer, T., Birk, S., Liedl, R., and Sauter, M.: Quantification of temporal distribution of recharge in karst systems from spring hydrographs, J. Hydrol., 348, 452-463, 2008.

Goldscheider, N.: Alpine Hydrogeologie, Grundwasser - Zeitschrift der Fachsektion Hydrogeologie, 16, 1, doi:10.1007/s00767-0100157-2, 2011.

Grasso, D. and Jeannin, P.-Y.: A Global Experimental System Approach of Karst Springs' Hydrographs and Chemographs, Ground Water, 40, 608-617, 2002.

Hauns, M., Jeannin, P.-Y., and Atteia, O.: Dispersion, retardation and scale effect in tracer breakthrough curves in karst conduits, J. Hydrol., 241, 177-193, 2001.

Haykin, S.: A Comprehensive Foundation, Macmillan New York, 1999.

Herz, J., Krough, A., and Palmer, R.: Introduction to the Theory of Neural Computation, Addison-Wesley, Reading, MA, 1991.

Jansson, P. and Karlberg, L.: Coupled heat and mass transfer model for soil-plant-atmosphere systems, Tech. rep., Web-Dokument: ftp://www.lwr.kth.se/CoupModel.pdf, Royal Institute of Technology, Dept of Civil and Environmental Engineering, Stockholm, 2001.

Kiraly, L.: Karstification and Groundwater Flow, Speleo, 1, 155190, 2003.

Kovacs, A., Perrochet, P., Kiraly, L., and Jeannin, P.-Y.: A quantitative method for the characterisation of karst aquifers based on spring hydrographs analysis, J. Hydrol., 303, 152-164, 2001.

Kraller, G., Strasser, U., and Franz, H.: Effect of Alpine karst on the hydrology of the Berchtesgadener Ache basin: a comprehensive summary of karst research in the Berchtesgaden Alps, eco.mont, 3, 19-28, 2011.

Kunstmann, H. and Stadler, C.: High resolution distributed atmospheric-hydrological modeling for Alpine catchments, J. Hydrol., 314, 105-124, 2005.

Kunstmann, H., Heckl, A., and Rimmer, A.: Physically based distributed hydrological modelling of the Upper Jordan catchment and investigation of effective model equations, Adv. Geosci., 9, 123-130, doi:10.5194/adgeo-9-123-2006, 2006a.

Kunstmann, H., Krause, J., and Mayr, S.: Inverse distributed hydrological modelling of Alpine catchments, Hydrol. Earth Syst. Sci., 10, 395-412, doi:10.5194/hess-10-395-2006, 2006b. 
Kurtulus, B. and Razack, M.: Modeling daily discharge responses of a large karstic aquifer using soft computing methods: Artifical neural network and neuro-fuzzy, J. Hydrol., 381, 101-111, 2010.

Langenscheidt, E.: Die Geologie der Berchtesgadener Berge, Berchtesgadener Anzeiger, 1994.

Lotz, A.: Alpine Habitat Diversity - HABITALP - Project Report 2002-2006, EU Community Initiative INTERREG III B. Alpine Space Programme, Tech. rep., Nationalpark Berchtesgaden, 2006.

Maloszweski, P., Buettner, G., Apel, R., Krafft, H., Scholz, M., and Wagner, B.: Quantitative evaluation of tracer experiments in Alpine Karst and Porous Aquifers in the National Park of Berchtesgaden, Lands, 48, 11-18, 2005.

Martinez Santos, P. and Andreu, J.: Lumped and distributed approaches to model natural recharge in semiarid karst aquifers, J. Hydrol., 388, 389-398, 2010.

Monteith, J.: Vegetation and the atmosphere, vol. 1: Principles, Academic Press, London, 1975.

Penman, H.-L.: Natural evaporation from open water, bar soils and grass, P. Roy. Meteorol. Soc. Lond. A, 193, 191-205, 1948.

Peschke, G.: Ein zweistufiges Modell der Infiltration von Regen in geschichtete Boeden, Acta Hydrophys., 22, 39-48, 1977.

Richards, L.: Capillary conduction of liquids through porous mediums, Physics, 1, 318-333, 1931.

Rimmer, A. and Salingar, Y.: Modelling precipitation-streamflow processes in karst basin: The case of the Jordan River sources, Israel, J. Hydrol., 331, 524-542, 2006.

Romanov, D., Gabrovsek, F., and Dreybrodt, W.: Modeling the evolution of karst aquifers and speleogenesis, The Step from 1-dimensional to 2-dimensional modeling domains, Speleogen. Evol. Karst Aquif., 2, 1-26, 2004.

Sauter, M., Kovacs, A., Geyer, T., and Teutsch, G.: Modellierung der Hydraulik von Karstgrundwasserleitern - Eine Uebersicht, Grundwasser, 3, 143-156, 2006.
Scanlon, B., Mace, R., Barret, M., and Smith, B.: Can we simulate regional groundwater flow in a karst system using equivalent porous media models? Case study, Barton Srpings Edwards aquifer, USA, J. Hydrol., 276, 137-158, 2003.

Schulla, J.: Model Description WaSiM (Water balance Simulation Model), Tech. rep., Hydrology Software Consulting J. Schulla, Zürich, Switzerland, 2012.

Siou, L., Johannet, A., Borrel, V., and Pistre, S.: Complexity selection of a neural network for karst flood forecasting: The case of the Lez Basin (southern France), J. Hydrol., 403, 367-380, 2011.

Strasser, U.: Modelling of the mountain snow cover in the Berchtesgaden National Park, Forschungsbericht 55, Nationalparkverwaltung Berchtesgaden, Berchtesgaden, 2008.

Teutsch, G. and Sauter, M.: Groundwater modeling in karst terrains: Scale effects, dam acquisition and field validation, 34d Conference on hydrogeology, ecology, monitoring and management of ground water in karst terranes, Nashville, USA, 17-35, 1991.

Van Genuchten, M.: Zur Messung und Schaetzung der potentiellen Verdunstung, Z. Meteorol., 25, 103-111, 1976.

Viviroli, D. and Weingartner, R.: The hydrological significance of mountains: from regional to global scale, Hydrol. Earth Syst. Sci., 8, 1017-1030, doi:10.5194/hess-8-1017-2004, 2004.

Weiler, M., McGlynn, B., Kevin, M., and McDonnell, J.: How does rainfall become runoff? A combined tracer and runoff transfer function approach, Water Resour. Res., 39, 1315-1327, 2003.

White, W.: Karst hydrology: recent developements and open questions, Eng. Geol., 65, 85-105, 2002.

White, W.: Conceptual models for karstic aquifers, Speleogen. Evol. Karst Aquif., 1, 1-6, 2003.

White, W. and White, E.: Conduit fragmentation, cave patterns and the localization of karst groundwater basins: the Appalachians as a test case, Speleogen. Evol. Karst Aquif., 1, 1-5, 2003.

Worthington, S.: A comprehensive strategy for understanding flow in carbonate aquifer, Speleogen. Evol. Karst Aquif., 1, 1-8, 2003. 